\title{
The Current Insurance Crisis and Modern Tort Law
}

\author{
George L. Priest $\dagger$
}

This paper is an effort to understand the source of the crisis in insurance that has recently disrupted product and service markets in the United States. From press accounts, the crisis seemed to peak in the early months of 1986, when reports became common of extraordinary changes in commercial casualty insurance markets. Insurers had increased premiums drastically for an unusual set of products, such as vaccines, ${ }^{1}$ general aircraft, ${ }^{2}$ and sports equipment, ${ }^{3}$ and for an equally diverse set of services, such as obstetrics, ${ }^{4}$ ski lifts, ${ }^{5}$ and commercial trucking. ${ }^{6}$ In still other cases-intrauterine devices, ${ }^{7}$ wine tasting, ${ }^{8}$ and day care, ${ }^{8}$-insurers had refused to offer coverage at any premium, forcing these products and services to be withdrawn from the market.

The crisis extended beyond commercial enterprises. Municipalities and other governmental entities faced similarly extreme premium increases or the unavailability of market insurance coverage altogether. Some cities closed jails and suspended police patrols until insurance coverage was ob-

+ John M. Olin Professor of Law and Economics, Yale Law School. I am very grateful to Rachel Eisner, Elliot G. Freier, David Leifer and J. Hoult Verkerke for research assistance; to Kenneth S. Abraham, William H. Adams III, Armen Alchian, Susan J. Bennett, Owen M. Fiss, Victor P. Goldberg, Henry B. Hansmann, Howard Kunreuther, Burke Marshall, A. Mitchell Polinsky, Roberta Romano, Ralph Saul, Gary T. Schwartz, Peter H. Schuck, Kate Stith, Ralph A. Winter, and especially Michael J. Trebilcock, for comments on earlier drafts; and to the Program in Civil Liability, Yale Law School, for support. I have benefited from discussions of this Article with groups of executives at the CIGN $\Lambda$ Corporation, with participants at the University of Houston Conference on Environmental Liability, and with members of faculty workshops at Yale and Vermont Law Schools. I am solely responsible for the contents.

1. Brody, When Products Turn into Liabilities, Fortune Mar. 3, 1986, at 20; Wall St. J., Jan. 21,1986 , at 31 , col. 1 .

2. Sorry, Your Policy Is Cancelled, Timk, Mar. 24, 1986, at 18; Brody, supra note 1, at 20.

3. N.Y. Times, Mar. 8, 1986, at 35, col. 3; Sorry Your Policy Is Cancelled, supra note 2, at 18.

4. U.S. Gen. Ac:counting; Offic:, Mridical. Mal.Pracitick: Insurance Costs Increased Burr Varifid Amoni: Physicians and Hosprtals 27 (1986).

5. N.Y. Times, Feb. 15, 1986, at 1, col. 1.

6. Toronto Globe \& Mail, Feb. 21, 1986, at B2, col. 1.

7. N.Y. Times, Feb. 1, 1986, at 1, col. 5; Wall St. J., Feb. 3, 1986, at 5, col. 1.

8. N.Y. Times, Mar. 26, 1986, at C12, col. 4.

9. Wall St. J., supra note 1. 
tained. ${ }^{10}$ Parks and forest preserves were closed. ${ }^{11}$ Fourth of July celebrations were cancelled because of concerns over uninsured liability. ${ }^{12}$

Over time, product manufacturers and service providers adjusted to these insurance difficulties. Recently, some commentators have interpreted the decline in the volume of complaints as evidence that the insurance crisis has subsided. ${ }^{13}$ But this is an incomplete and unrealistic view of the problem. Although there has allegedly been some increase in insurance availability, the huge premium increases of early 1986 are largely intact, ${ }^{14}$ necessitating sustained price increases and reducing demand for affected products and services. Moreover, many of the effects of the crisis have become permanent. A recent Conference Board study of liability problems of the country's largest corporations-those whose size and self-insurance capability make them least vulnerable to changes in commercial insurance markets-reports that twenty-five percent had removed products or withdrawn services from the market. ${ }^{15}$ The effect on national income of increased prices and the withdrawal of products and services is obvious.

Similarly, there have been long-term effects of the insurance crisis on municipalities and government entities. Many municipalities have responded to the crisis by altering the array of public services, sometimes radically. Some cities have removed all playground equipment from their public parks. ${ }^{16}$ Diving boards have been removed from school swimming pools. ${ }^{17}$ Many municipalities denied market insurance (as well as some commercial entities) have continued operations after joining mutual insurance groups. ${ }^{18}$ As we shall see, the actual insurance protection provided by industry-wide or municipal mutual insurance pools may largely be illusory, only postponing the effects of expected liability for some uncertain period. ${ }^{19}$ At the least, the sudden growth in the frequency of mutual insurance is reflective of the extremely fragile character of today's commercial casualty insurance industry.

10. Sorry, Your Policy Is Cancelled, supra note 2, at 17-18; N.Y. Times, Mar. 4, 1986, at A26, col. 1 (editorial).

11. N.Y. Times, May 12, 1986, at 1, col. 1.

12. N.Y. Times, June $15,1986, \S 23$, at 1, col. 4; Wall St. J., June 6 , 1986, at 27, col. 1; New Haven Register, May 15, 1986, at 1, col. 1.

13. N.Y. Times, Feb. 19, 1987, at 1, col. 5.; Wash. Post, Jan. 15, 1987, at A20, col. 1 (editorial); Wash. Post, Jan. 5, 1987, at 18, col. 1-4.

14. N. Wriber, Pronuct Liabil.try: The Corporate Response 4-7 (Conf. Bd. 1987) [hereinafter Conf. Bd.]; Glaberson, Liability Rates Flattening Out as Crisis Eases, N.Y. Times, Feb. 9, 1987, at 1, col. 5; Wall St. J., Jan. 6, 1987, at 64, col. 2 (malpractice insurance costs continue to rise despite tort reform); Wash. Post, Jan. 5, 1987, at 18, col. 1 .

15. Conf. Bd., supra note 14, at 15-16.

16. Sorry, Your Policy Is Cancelled, supra note 2, at 24.

17. Governor's Anvisory Comm'n on Liabil.ITy Insurance, Insuring OUR Future 15, 24

(1986) (New York City Schools) [hereinafter Cuomo Comm'N].

18. See infra text accompanying notes 237-39 \& note 239.

19. See infra text accompanying notes 240-43. 
Three sets of theories have been put forth to explain the insurance crisis and to propose its cure. The first set views the crisis as collusively engineered by insurance companies, either by explicit price-fixing or by financial manipulation of insurance reserve accounts. ${ }^{20} \mathrm{~A}$ second set of theories explains the crisis with reference to the cyclical effect of changes in interest rates on investment returns and, thus, on insurance premiums. According to this theory, the crisis is the direct result of recent declines in interest rates which have forced insurance premiums to increase. ${ }^{21}$ In a slightly different version, the crisis is attributed to an earlier period of high interest rates during which insurers, shortsightedly, underpriced risks to gain premiums for investment, risks which must be recalculated at higher premiums today. ${ }^{22}$ The collusion and the insurance cycle theories both imply that these insurance problems will disappear in time, either through the breakdown of the cartel (or by antitrust enforcement or regulation), ${ }^{23}$ through the cyclical return of higher interest rates, or through the more accurate evaluation of risks by chastened insurers.

A third theory, most prominently espoused by the Justice Department, attributes the crisis to modern tort law's expansion of corporate liability exposure, which has necessitated insurance premium increases. ${ }^{24}$ According to the Justice Department, only wide-ranging tort law reform can cure the crisis. Within the past eighteen months, on the basis of the Department's and other attributions of the crisis to tort law, forty-two states have enacted tort reform or insurance legislation. ${ }^{25}$ Although there are differences among the states, the general similarity in approach and the sudden spontaneity of the response represent the most extraordinary state law development having national impact since the states' unanimous

20. See Goldberg, Manufacturers Take Cover, A.B.A. J., July 1, 1986, at 52, 55 (quoting Jay Angoff, Nat'l Ins. Consumer Org.); The Liability Crisis: Who's To Blame?, 6 ManhatTAN ReP. 1, 9 (1986) (discussant's comment); Statement of J. Robert Hunter, Medical Mut. Liab. Ins. Soc'y of Md. (July 1, 1985). For a discussion of this theory, see infra text accompanying notes 39-45.

21. See F. Bellotti, J. Van de Kamp, L. Thornburg, J. Mattox, C. Brown \& B. La Follette, An Analysis of the Causes of the Current Crisis of Unavailability and Unaffordability of Liability Insurance (Nat'l $\Lambda$ ss n of Attorneys Gen., $\Lambda \mathrm{d}$ Hoc Comm. on Ins., May, 1986) (unpublished manuscript). This theory is discussed infra at text accompanying notes 46-58.

22. See, e.g., Goldberg, supra note 20, at 55 (quoting Frank Nutter, President, Alliance of American Insurers). For a discussion of this theory, see infra text accompanying notes 47-58.

23. Recently, Florida and Hawaii have instituted new rate regulation of commercial casualty insurance lines allegedly to constrain insurer profit gouging. Several other state legislatures are considering regulation of this nature.

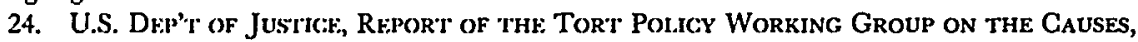

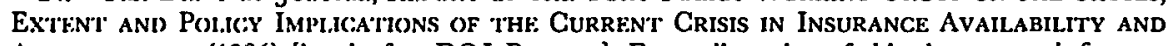
AFFORDABILITY (1986) [hereinafter DOJ RHPOR'r]. For a discussion of this theory, see infra text accompanying notes 59-71.

25. For a summary, see Nar't. Conftrknce. of Sita'te Legisl.atures, Sfi.fcted State Leg-

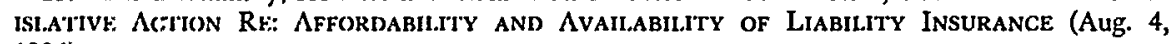
1986). 
adoption of the Uniform Commercial Code. ${ }^{26}$ Indeed, the Justice Department now claims that this legislation-though in effect only for scant months-has largely cured the insurance problem. ${ }^{27}$

None of these three theories, however, fully or adequately explains the phenomena of the recent insurance crisis. Virtually all commentators, in characterizing the crisis, have focused solely on the sudden increases in insurance premiums and the occasional withdrawal of insurance coverage during early 1986. The crisis, however, has been attended by a much broader group of related phenomena, which must be addressed by any comprehensive explanation. For example, long before 1986, there began to occur increasing shifts toward corporate self-insurance for expected tort liability. In addition, in recent months, while simultaneously increasing premiums, insurers have fundamentally redrafted the basic commercial insurance policy-raising deductibles, lowering levels of aggregate coverage, and revising specific policy exclusions. A comprehensive theory of the crisis must account for all of these phenomena, and must explain their peculiar concentration within commercial casualty lines only, rather than across the broad range of insurance offerings. None of the three existing theories of the insurance crisis can do so.

This paper provides a different theory of the crisis. It attributes these changes in insurance coverage to modern tort law, but by a mechanism much different from that suggested by the Justice Department. In my view, it is simplistic to no more than assert a connection between expanding tort liability and the disruption of insurance coverage. The relationship between legal liability and the insurance function obviously is more complicated: The demand for commercial insurance coverage derives from tort liability. The expansion of tort liability might well create opportunity, rather than crisis, for the insurance industry.

This paper argues that the characteristic of contemporary tort law most crucial to understanding the current crisis is the judicial compulsion of greater and greater levels of provider third-party insurance for victims. The progressive shift to third-party corporate insurance coverage, since its beginnings in the mid-1960's, has systematically undermined insurance markets. The decline in interest rates within the past two years has led the most fragile of these markets-those for which third-party coverage is least supportable-to collapse. The collapse is signalled by the accelerating conversion to self-insurance. This conversion, in turn, forces insurers to exact drastic premium increases, as well as to restructure the terms of

26. It should be remembered that the 42 nd adoption of the U.C.C. occurred in 1965, 12 years after the first adoption in 1953.

27. Noble, Liability Insurance Reported Easier To Get Than Year Ago, N.Y. Times, Mar. 27, 1987, at D18, col. 1 (quoting Justice Department press release). 
the basic insurance policy, in order to salvage a market among remaining insureds. Where these salvage efforts have proven unsuccessful, insurers have refused to offer coverage altogether.

This explanation of the crisis uncovers what I believe to be a tragic paradox of our modern civil liability regime. The expansion of liability since the mid-1960's has been chiefly motivated by the concern of our courts to provide insurance to victims who have suffered personal injury. ${ }^{28}$ The most fundamental of the conceptual foundations of our modern law is that the expansion of tort liability will lead to the provision of insurance along with the sale of the product or service itself, with a portion of the insurance premium passed along in the product or service price. Expanded tort liability, thus, is a method of providing insurance to individuals, especially the poor, who have not purchased or cannot purchase insurance themselves. This insurance rationale suffuses our modern civil law, and must be acknowledged as one of the great humanitarian expressions of our time.

The paradox exposed by my theory is that the expansion of tort liability has had exactly the opposite effect. The insurance crisis demonstrates graphicly that continued expansion of tort liability on insurance grounds leads to a reduction in total insurance coverage available to the society, rather than to an increase. The theory also shows that the parties most drastically affected by expanded liability and by the current insurance crisis are the low-income and poor, exactly the parties that courts had hoped most to aid.

Section I reviews the three existing theories and shows their inability to explain the insurance crisis. Sections II through V, then, present the theory of the paper itself. Section II demonstrates the economic effects, including the insurance effects, of tort rules. Section III describes the operation of private insurance markets. This Section shows why insurance exists, how insurance markets are defined, and how they must be maintained in order to survive. Section IV applies these insurance principles to explain the theoretical reasons that expanding liability is likely to affect private insurance markets. Section V examines the details of the recent insurance crisis in light of this theory. It explains why the insurance problems created by modern tort law have led particular providers, ${ }^{29}$ especially municipalities, to cancel market insurance and to self-insure; how the shift to self-insurance has forced insurers to change the terms of insurance contracts or, in some cases, to refuse insurance coverage on any

28. See Priest, The Invention of Enterprise Liability: A Critical History of the Intellectual Foundations of Modern Tort Law, 14 J. Lk.cial. Srud, 461 (1985) [hereinafter Enterprise Liability].

29. The term provider refers to producers of goods (manufacturers) and services (other than insurers), including government entities. 
terms; and why such changes in insurance markets harm principally the low-income and poor and, in many cases, benefit the high-income and wealthy. Finally, Section VI discusses why the crisis has affected the particular industries that it has and why the recent tort reform legislation in the various states is unlikely to solve the insurance problems our society faces.

This paper concludes that insurance markets can be stabilized only if courts recognize the adverse insurance consequences of expanded provider liability. Stabilizing current markets, however, is not equivalent to restoring their earlier vitality. Insurance markets can be widely restored in our society, and the scope of insurance expanded, only by a radical reconceptualization and redefinition of substantive tort law standards. The recently enacted tort reform legislation in the various states and even the more ambitious proposals of the Justice Department may serve as a temporary stop-gap, but they are unlikely to achieve stable reform because they do not challenge systematically the deeper source of the crisis: the failure of our courts to understand how legal rules affect the insurance function.

\section{Three Gurrent Theories and Their Explanatory Failures}

In order to evaluate the collusion, insurance cycle, and the Justice Department's tort law theories, it is necessary to describe the history and manifestation of the insurance crisis in greater detail. Property/casualty insurance premiums have been increasing steadily since the early 1980's and probably before. ${ }^{30}$ Simultaneously, an accelerating shift toward selfinsurance has occurred in certain commercial casualty insurance lines. For example, over this period, growing numbers of doctors and other professionals have formed small mutual insurance groups instead of continuing to purchase malpractice insurance from market carriers. Some doctors, after shielding their assets, have continued to practice uninsured. ${ }^{31}$ Similarly, increasing numbers of manufacturers have dropped market insurance in favor of the creation of captive offshore insurance subsidiaries. ${ }^{32}$ At about the same time, in the early 1980's, insurers initiated efforts to restrict coverage levels in certain commercial lines by changing the terms of the basic policy from an occurrence to a claims-made basis. ${ }^{33}$

\footnotetext{
30. Conf. Bd., supra note 14, at 4 (Table 2); Wyatr Co., 1985 Dirkcrors and Officers LiabII.TIY SURVEY 17 (1985).

31. Patricia Danzon reports that, as of 1985 , over $40 \%$ of medical malpractice insurance was written by small mutual or captive insurance firms. P. Danzon, Mrdicil. Mal.Pracirice 93 (1985). For estimates of doctors who practice uninsured, see Zuckerman, The Costs of Medical Malpractice, 3 HraI:TH AFFaIRS 128, 132-133 (1984).

32. See Insurance. Services Office, Inc., The Coming; Capacitry Shortace: 11 (1985).

33. See Insurance: Skrvices Office, Inc:, Comprehtensive: Genkral Liability Poi.icy (2d ed. 1985). See generally Americin Insurance: Associtation, Productr Liabititry Insurance 23
} 


\section{The Current Insurance Crisis}

The crisis of early 1986 consists only of a sharpening of these broader trends. As premiums increased, larger numbers of firms consciously decided to self-insure by establishing their own reserves. ${ }^{34}$ The basic commercial insurance policy was revised more drastically: the claims-made policy was adopted almost universally, deductibles were raised, aggregate policy limits were lowered, and greater numbers of specific coverage exclusions were incorporated. ${ }^{35}$ Despite these reductions in insurance coverage, premiums in many commercial casualty lines were increased by extraordinary amounts: in some cases by $400 \%, 1000 \%, 1500 \%$, and more. ${ }^{36}$ In some lines, such as coverage for nurse-midwives, municipalities, and day care centers, many insurers refused to offer coverage at any premium. ${ }^{37}$

It should be emphasized that these drastic changes in insurance coverage occurred despite any evidence of increases in the underlying riskiness of the products or services affected by the crisis. Indeed, a recent study of underlying levels of risk asserts that injury rates have successively declined over time for almost all injury categories. ${ }^{38}$

To explain the modern crisis fully, a theory must account for all of these phenomena. It must explain not only the increase in insurance premiums, but also the trend toward self-insurance, the restructuring of the insurance contract, and the refusal of insurers to offer coverage in some markets at any premium. Such an explanation must also show why these changes occurred only within commercial casualty insurance lines and not in auto, life or health insurance lines and why these changes occurred despite any evident increase in the underlying accident or injury rate. None of the three existing sets of theories of the crisis does so.

\section{A. Collusion Theories}

It is a very common view that the insurance crisis has been caused by explicit price-fixing by commercial casualty insurers. ${ }^{39}$ The price-fixing hypothesis, however, is implausible on its face. Obviously, the sudden in-

(1979) (describing claims-made policy).

34. N.Y. Times, Mar. 8, 1986, at 35, col. 3; see Conf. Bd., supra note 14, at 3 (Table 1); Business Week reports that, "Before the crisis, ... 'self-insurance' totaled no more than $25 \%$ of the market. Now, it's about 33\% and growing." The Crisis Is Over but Insurance Will Never Be the Same, Bus. WEkK, May 25, 1987, at 122, col. 1, 3. Others have estimated the current extent of selfinsurance as constituting $25 \%$ to $47 \%$ of the property/casualty market. See infra note 193.

35. For specific examples of these changes, see infra text accompanying notes 194-215.

36. Compare the recent changes in premium-to-coverage ratios, infra text accompanying notes 216-21.

37. See infra text accompanying notes 225-31.

38. T. Sc:Hit.l.ING, An Eiconomist Looks at Risk and Liability, in RISK, COMPENSATION, AND Liabil.try: The: Polic:y Choices 53-55 (1986).

39. See, e.g., The Liability Crisis: Who's To Blame?, supra note 20, at 9 (discussant's comment). 
crease in premiums is consistent with price-fixing. Collusion, however, cannot explain why the basic insurance policy has been restructured. Except in very rare circumstances involving forms of localized price discrimination, monopolistic and competitive industries will offer products identical in all characteristics except price. ${ }^{40}$ The commercial casualty insurance lines, in fact, are the least likely to support successful collusion because of the highly individualized character of commercial underwriting. In these lines, the extension or exclusion of coverage very frequently is individually tailored for specific firms, which makes pricing agreements among competitors extremely difficult, if not impossible, to police. ${ }^{41}$ Finally, the refusal of insurers in several commercial lines to offer coverage at any premium is totally inconsistent with collusion. Since antitrust enforcement began in the 1890's, there have been very few examples of monopolists or conspirators who have rebuffed consumers begging to pay any price for a product, as insurers have rebuffed nurse-midwives and day care operators, among others.

A variant of the price-fixing theory is the claim that the crisis has been concocted by concerted manipulation of insurer financial accounts. According to this explanation, representations of the insurance industry's precarious financial position are gross exaggerations, designed to mislead legislators and the public about the need for tort reform. ${ }^{42}$ In recent months, there has been heated debate over the implications of very recent increases in reported insurance industry earnings, ${ }^{43}$ a debate which derives from claims of this nature.

The manipulation claim is fueled by the unusual character of insurance company accounting. Insurance company profits are the net of premium plus investment returns less losses (payouts and expenses). Losses, of course, are often paid out years after the receipt of premiums. To calculate a current year profitability against collected premiums, insurers report a figure called incurred losses which consists of the sum of losses

40. Schwartz \& Wilde, Imperfect Information in Market for Contract Terms: The Examples of Warranties and Security Interests, 69 VA. L. Rr.v. 1387, 1414 (1983). See generally Rosen, Hedonic Prices and Implicit Markets: Product Differentiation and Pure Competition, 82 J. POL. EcoN. 34 (1974).

41. For the same reason, the regulation of prices and terms in the casualty insurance industry is likely to be ineffective. See Stewart, Remembering a Stable Future, address delivered at ISO-III Industry Conf., Jan. 14, 1987 (unpublished manuscript on file with author).

42. See Goldberg, supra note 20 , at 55 (quoting Jay Angoff, Nat'l Ins. Consumer Org.).

43. See, e.g., U.S. Gen. Accounting Office, Statement of William J. Anderson, Director, Gen. Gov't Div. Before the Subcommittee on Oversight, Committee on Ways and Means, House of Representatives, on Profitability of the Property/Casualty Insurance Industry 8 (Mar. 13, 1986) (underwriting losses have bottomed out; industry will have substantial net gains over next five years); U.S. Gen. Accounting Office, Statement of Johnny C. Finch, Senior Associate Director, Gen. Gov't Div., Before the Subcommittee on Oversight, Committee on Ways and Means, House of Representatives, on Profitability of the Property/Casualty Insurance Industry $5(\Lambda$ pr. 28,1986$)$ (industry profitable over long term). 
already paid, unpaid losses where the loss-generating event has occurred, and what are known as "losses incurred but not reported." 44 Losses incurred but not reported (IBNR) are in essence estimates by insurers of claims that will be, but have not yet been, filed against the current policy.

The insurance industry has justified recent large premium increases, and the restrictions introduced in coverage within the past year, by showing an excess of incurred losses over premium and investment returns. But the largest component of these incurred losses has been IBNR, which of course represents estimated rather than actually paid amounts. The manipulation claim is that insurers have inflated IBNR estimates in order to suggest financial insecurity in the insurance industry and, thus, the need for tort reform. ${ }^{45}$

There is no doubt that IBNR amounts, as estimates, are manipulable. IBNR amounts can never be subjected to definitive evaluation. The manipulation of IBNR, however, can account for only a small set of the phenomena of the insurance crisis. Even if insurers can gain from financial manipulations of this sort, there is no plausible reason why insurers have manipulated IBNR amounts only in commercial casualty lines, rather than in other lines (such as auto or domestic casualty), where payouts might also be reduced by changes in the law. In addition, the alleged manipulation of IBNR would not explain why the insurance contract has been restructured to reduce levels of insurance coverage. Similarly, why have insurers withdrawn from some markets entirely, refusing to offer coverage at any premium? The manipulation theory cannot answer this question.

\section{B. Insurance Cycle Theories}

Probably the most prominent explanation of the crisis is the insurance cycle theory. According to this theory, insurance premiums were low during the late 1970's and early 1980's because interest rates and investment returns were high. In recent years, as interest rates have fallen with the decline in inflation, insurers have been forced to increase insurance premiums. ${ }^{46}$ The crisis, thus, is no more than a predictable response to exogenous financial movements. It follows that, in the future, as interest rates return to higher levels, insurance premiums will decline and the crisis will pass. A common variant of the insurance cycle theory adds a claim of cut-

44. See AMtrican Insuranc: Association, supra note 33, at 9, 44-47, 65-67, 72-73; R. Mehr \& E. Cammack, Principl.js of Insuranc:k 600-03 (6th ed. 1976).

45. See Goldberg, supra note 20 , at 55 (citing Jay Angoff's claim that rate increase is part of effort to convince legislators of "crisis in the courts").

46. This is the principal explanation of the Cuomo Commission. See Cuomo Comm's, supra note 17 , at 10-11. 
throat competition to the account. According to this version, during the days of high interest rates in the early 1980's, insurers wrote policies promiscuously, taking on any risks to accumulate premiums for investment. Now the industry has learned how myopic the scramble for insurance premiums was. Risks that should have been expected to be poor are only now being discovered to be poor. ${ }^{47}$ Premiums must be raised to reflect underlying risks more accurately. ${ }^{48}$

Insurance cycle theories are superficially plausible because, in fact, premium cycles related to financial returns are inevitable. During the period between receipt of policy premiums and payoff of subsequent claims, insurers gain substantial returns from investment income. Competition among insurers forces them to lower premiums as investment gains rise and to raise premiums as investment returns fall. It follows that, to the extent insurers have invested in variable interest obligations, premiums will rise as interest rates decline, and the reverse. It is uncontrovertible that interest rates have declined since the early 1980's.

The insurance cycle theory, however, provides only a very partial explanation of the crisis. First, it seems unlikely that recent alterations in insurer investment portfolios provide a full explanation of the extraordinary premium increases observed during the current crisis. ${ }^{49}$ Over the past two years, interest rates have declined only modestly. Moreover, insurers can hedge against interest rate changes by choice of investment portfolio. Common stock and many land investments, for example, have increased in value substantially. ${ }^{\text {.0 }}$ Second, the insurance cycle theory does not explain why the current crisis has occurred only in selected commercial casualty lines. Declines in interest rates and investment income affect all insurance premiums. Over the past two years, for example, auto and household premiums have risen modestly (four to nine percent annually), ${ }^{\mathbf{s 1}}$ at rates that correspond to the real rate of interest, but that do not remotely resemble rates of increase in commercial casualty premiums. Third, changes in investment returns do not account for the most puzzling feature of the crisis: the refusal of insurers to offer coverage at any premium. The insurance cycle alone may lead to periodic insurance premium

47. See Insuranck: Skrvichs Offick, Inc., 1985: $\Lambda$ Critical. Ykar 4 (1985); Goldberg, supra note 20, at 55 (quoting Frank Nutter, President of American Alliance of Insurers).

48. $\Lambda$ more implausible argument holds that premiums must be raised to make up for past losses. This account ignores the highly competitive character of the commercial casualty industry that would prevent recoupment.

49. I am aware of no study that has attempted rigorously to demonstrate this relationship.

50. For the aggregate portfolio of property/casualty insurers, see Insurance: INFoRMarton INSI., 1986-87 PROPFR'YY/CASUAI:IY FAC:I BOOK 23 (1986). Industry investment income increased during 1985 by $10.5 \%$. Id. at 20 . Note also the simultaneous increases in payouts of self-insurers who maintain no reserve portfolio, such as New York City. See Cuomo Comm'N, supra note 17, at 35-36.

51. INSURANCE. INFORMATION INSITIUTE, supra note 50, at 49-50. 
adjustments, but it does not compel withdrawal from the business of offering insurance altogether.

Some commentators have tried to explain coverage restrictions and the concentration of the crisis in commercial casualty lines, by asserting a constraint on total insurance capacity. If insurers have reached an upper bound to the aggregate coverage they can write, then as insurers face either a larger pool of risks or a smaller addition to surplus from investment returns, they must reduce total coverage either by terminating some current policies, reducing levels of coverage within current policies, or both. An insurance capacity limitation, thus, might explain why insurers restructured contracts to lower coverage levels and why they withdrew from some markets altogether-in particular, highly risky commercial casualty lines. $^{52}$

The sources of the alleged insurance capacity constraint, however, are mysterious. Supporters of the theory invoke the behavior of some state insurance commissions, which prohibit insurers from exceeding a premium-to-surplus ratio of $4: 1$ and often recommend a ratio of 3:1. ${ }^{53}$ More generally, commission or not, the 4:1 premium-to-surplus ratio is widely regarded as a "prudent" insurer objective. ${ }^{54}$ Other commentators invoke the reinsurance market as a capacity constraint. ${ }^{\mathrm{DS}}$ It is widely known that European reinsurers have drastically reduced underwriting capacity in U.S. markets.

The limited capacity explanation, however, is not generally helpful. First, it is not clear that insurance capacity has been exhausted. The property/casualty premium-to-surplus ratio in December 1984 was 1.85:1, and in December 1985 (the most recent statistic available) was $1.91: 1{ }^{\text {, }}$ both figures are far below the "prudent" or commissionmandated ratios of 4:1 and 3:1. ${ }^{57}$ Second, even within specific insurance

52. This argument is relied upon heavily by the Cuomo Commission. See, e.g., Cuomo Comm'N, supra note 17 , at 15 .

53. See R. Rikciki., J. Mil.t.er \& C. Willi.iams, Insurance. Principlegs and Pracirices 567-89 (6th ed. 1976); Insurance: Sirvicis Office, Inc., supra note 32, at 14. The premium-to-surplus ratio regulations are promulgated under insurance commissions' authority to ensure that insurers remain solvent. See, e.g., Iowa Conk $\$ 505.8$ (1983).

54. See Insuranc:e Srrvicis Offick, Inc., supra note 32, at 5, 14.

55. Cucomo Comm's, supra note 17, at 27-28.

56. These ratios were obtained by dividing industrywide net premiums written in 1984 and 1985 , Insuranc: Infokmation InsitruTt, 1986-87 Property/Casual.Ty Fact Book 24 (1986), by industry-wide policyholder's surplus at the end of the respective years, id. at 18. "Net premiums written" is defined as "premium income retained by insurance companies, direct or through reinsurance, less payments made for business reinsured"; "policyholder's surplus" is the "[s]um left after liabilities are deducted from assets . . [,] the financial base that permits a company to sell insurance." Id. at 112.

57. Of course, the premium-10-surplus ratio must be calculated at the firm level for individual insurance lines. It is within an insurer's judgment, however, to reallocate surplus and capacity from one line to another. In addition, even if some individual firms exceed the $3: 1$ or $4: 1$ ratio, the industrywide figure shows that other firms have resources that could be allocated to these lines. For a descrip- 
lines, the premium-to-surplus ratio can be altered by insurer adjustments to surplus by means of (admittedly manipulable) IBNR entries or, more legitimately, by reinsurance agreements or capital formation. Reinsurance availability has surely declined, but this fact cannot be an explanation of the insurance crisis in the United States. Reinsurance capacity measures the extent to which reinsurers are willing to invest in U.S. markets; the decline in reinsurance capacity, thus, is the problem to be explained. What must be determined is why individual insurers and reinsurers have concluded that they cannot make money in commercial casualty insurance lines, despite the presence of insureds who are pleading for coverage. ${ }^{58}$

\section{The Justice Department's Tort Law Theory}

In a highly influential report, the United States Department of Justice has attributed the insurance crisis to increases both in tort claim frequency and in the size of damage recoveries in successful tort actions and settlements. The report documents an increase of $758 \%$ in federal product liability actions from 1974 to $1985,,^{58}$ a doubling of the rate of medical malpractice lawsuits from 1976 to 1981 , and an increase of $141 \%$ in claims against municipalities from 1979 to $1983 .^{60}$ Overall, average damage awards have increased by fifteen percent annually since $1975 .{ }^{61}$ The Department claims, in addition, that tort law rules have become more uncertain in recent years, exacerbating the effects of increasing claims and damages. ${ }^{62}$ The results of the study led the Department to recommend a wideranging set of tort law reforms, including reinstating a fault liability standard, adopting scientific, rather than less stringent legal, causation standards, instituting a cap on non-economic damages, and eliminating joint and several liability, among others. ${ }^{63}$ The argument put forth by the Justice Department's report has provided the principal justification for the enactment of diverse state legislation incorporating many of the Department's proposed reforms. ${ }^{64}$

The Justice Department's conclusions have been contested, most vigor-

tion of the distribution of premium-to-surplus ratios across firms, see Insurance Services OfFICE, INC:., 1985: $\Lambda$ CRITICAL. Y YAR 18-19 (1985).

58. For an interesting, but to my mind, unproven theory of the premium cycle, based on the administrative costs of adjusting capacity levels, see R. WINTER, "CRISEs" IN Competrtive INSURANC:E MakkFis (Hoover Institution Working Papers in Economics E-86-74 (Dec. 1986)).

59. DOJ RFPOR', supra note 24 , at 45.

60. Id. at 47.

61. Id.

62. Id. at 51 .

63. Id. at 60-75.

64. Of course, there has been extensive industry lobbying for tort reform legislation. See, e.g., The Need for Legislative Reform of the Tort System: A Report on the Liability Crisis from Affected Organizations (1986) (lobbying memorandum of 140 trade associations and other organizations on file with author). 
ously in a study by the National Center for State Courts ${ }^{65}$ which analyzed changes in state court, rather than federal court, filings. Of course, the very largest proportion of tort actions originate in state, not in federal, courts. The Center claims to find "no evidence to support the . . . existence of a national 'litigation explosion' in state trial courts during the 1981-84 time period." decrease in litigation volume in the twenty states for which statistics were reported. ${ }^{67}$

Neither the Justice Department's nor the National Center for State Courts' statistics, however, is convincing. Although state court statistics provide the better index of tort litigation, the Center's study is misleading because its data are so highly aggregated. The volume of civil complaints and trials is dominated by auto collision, slip and fall, and other kinds of property injury cases, ${ }^{68}$ which no one claims are affected by the current insurance crisis. Thus, an aggregate leveling or even decline in tort litigation may conceal substantial litigation increases in the specific areas of commercial activity most seriously affected.

The Justice Department's study, in contrast, does report caselaw trends in fields subjected to substantial premium increases or withdrawals of insurance coverage. Yet the Justice Department's study falls far short of documenting the source of the current crisis. The increase in rates of claims and size of damage awards reported by the Justice Department are far smaller than reported increases in insurance premiums. The report cites a $758 \%$ increase in federal product liability filings, but over an eleven year period, 1974-1985. ${ }^{69}$ The increase in federal products liability filings from 1984 to 1985 was only about twenty percent. The increase in average damages awarded was about eighty percent, but it followed a drop of nearly twenty-five percent from $1983-1984 .{ }^{70}$ Similarly, the number of malpractice actions more than doubled, but over a five-year period; claims against municipalities increased $141 \%$ percent, but over a four-year period. ${ }^{71}$ No trial or settlement statistics, however, have shown increases that

65. Nat'l. Chantrir for Strate Courts, a Preliminary Examination of the Available Civil. and Criminal. Trend Data in State Trial Courts for 1978, 1981 and 1984.

66. Id. at 2.

67. Id.

68. See M. Pzitrisson \& G. Prifst, The Givil. Jury: Trends in Trials and Verdicts, Cook Counry, Ir.t.inois, 1960-1979, at 7, Figure 1 (Rand Corp. R-2881-ICJ 1982).

69. DOJ REPOR'; supra note 24 , at 45.

70. Id. at 46 (filings data from $\Lambda \mathrm{dmin}$. Office of U.S. Courts); $i d$. at 38 (average products liability jury verdict data from Jury Verdict Research, Inc.). Note that it is unclear whether the data on average award is based on state cases, federal cases, or a sample of both. It is also worth noting that "the reported average annual verdicts are not used by the Working Group as an accurate statement (though they may very well be) of the average jury verdict in any particular year." Id. at $36 \mathrm{n} .33$. I am skeptical of the Jury Verdict Research data because they make no pretense of being representative.

71. Id. at 45, 47. These figures appear to include suits in both federal and state courts. 
even remotely correspond to the increases in insurance premiums at multiples of four, five, ten, fifteen, and more over a period of a few months.

Other commentators have criticized even the attempt to relate past tort payouts to current insurance premiums. Both Michael Trebilcock and Richard Epstein, for example, have argued that current premium levels need not relate in any way to past claims experience. Current premiums, instead, are set with respect to estimates of future claims experience. ${ }^{72}$ In this view, insurance premiums represent a form of futures market for expected claims, just as stock prices reflect estimates of future corporate income.

Analytically, this proposition is surely correct. Yet there remains substantial reason to be skeptical as to why insurers, observing rapid (but not extraordinary) increases in claim frequency and damage levels over many years, would suddenly predict future increases at unprecedented levels. Nevertheless, like insurer estimates of IBNR, there is no way definitively to evaluate this kind of insurer calculation. Thus, however accurate the depiction of the relation between current premiums and future claims, the relation is unhelpful. It provides us with no method for determining the source of the crisis.

None of the three theories, then, can adequately explain the current crisis. Sections II through V of this Article set forth a different theory. They attempt to show precisely how changes in tort liability have undermined specific insurance markets, leading to the recent crisis. Section II briefly describes the direction of modern tort law and its economic effects.

\section{MOdern TORT LAW ANd Its Economic Effects}

Since the early 1960 's, courts have steadily expanded tort liability for injuries suffered in the context of product and service use. These changes in the law result from the acceptance of a coherent and powerful theory that justifies the use of tort law to compensate injured parties, a theory its founders called "enterprise liability." 33 According to the theory, expanded provider liability serves three important functions: to establish incentives for injury prevention; to provide insurance for injuries that cannot be prevented; and to modulate levels of activity by internalizing costs, including injury costs. ${ }^{74}$

72. M. Trebilcock, The Social Insurance-Deterrence Dilemma of Modern North American Tort Law, 3-4 (2d draft Jan. 1987) (unpublished manuscript on file with author); Epstein, Shooting the Insurance Messenger, Chicago Tribune, May 30, 1986, § 1, at 25, col. 1.

73. See generally $\Lambda$. Ehrenzweic; Nh.gligence. Without Fault (1951). For a discussion of the influence of this theory on modern tort law, see Enterprise Liability, supra note 28, at 519-27.

74. See Landes \& Posner, A Positive Economic Analysis of Products Liability, 14 J. LeGaL Srud. 535 (1985); Shavell, Strict Liability Versus Negligence, 9 J. LEGAL STud. 1 (1980). 
The second feature of the theory - the importance of providing insurance for unpreventable losses-is most crucial for understanding our current insurance crisis. According to enterprise liability theory, expanded legal liability does more than achieve optimal control of accident and activity rates. Expanded tort liability improves social welfare, in addition, because it provides a form of compensation insurance to consumers. A provider, especially a corporate provider, is in a substantially better position than a consumer to obtain insurance for product- or service-related losses, because a provider can either self-insure or can enter one insurance contract covering all consumers-in comparison to the thousands of insurance contracts the set of consumers would need-and can easily pass the proportionate insurance premium along in the product or service price. Most importantly, to tie insurance to the sale of the product or service will provide insurance coverage to consumers who might not otherwise obtain first-party coverage, in particular the poor or low-income among the consuming population. ${ }^{75}$

The insurance rationale was central to the first judicial adoption of enterprise liability theory, by the California Supreme Court in Greenman v. Yuba Power Products, ${ }^{76}$ in 1963. The approach was rapidly extended across the various state jurisdictions, first in the products liability field and, later, in other areas of tort law. ${ }^{77}$ Briefly, however, enterprise liability theory has justified both restrictions in available legal defenses and expansion of substantive liability standards.

As examples, since the mid-1960's, courts have invoked the insurance rationale to limit the defenses of contributory negligence, ${ }^{78}$ assumption of risk, ${ }^{79}$ and consumer product misuse; ${ }^{80}$ to eliminate defenses related to the

75. See Enterprise Liability, supra note 28 , at 462-64. For a more detailed recounting of the concern of courts with providing insurance to the poor, see Priest, Protecting the Poor Through Tort Law (unpublished manuscript on file with author).

76. 59 Cal. 2d 57, 377 P.2d 897, 27 Cal. Rptr. 697 (1963) (in bank). This case is discussed in Enterprise Liability, supra note 28, at 505-11.

77. This paper cannot review these developments in detail. For a more thorough discussion, particularly of products liability law, see Enterprise Liability, supra note 28, at 496-519. See generally Escola v. Coca Cola Bottling Co., 24 Cal. 2d 453, 461, 150 P.2d 436, 440-42 (1944) (in bank) (Traynor, J, concurring) (now classic statement of enterprise liability rationale).

78. See Luque v. McLean, 8 Cal. 3d 136, 145-46, 501 P.2d 1163, 1169-70, 104 Cal. Rptr. 443, 449-50 (1972); McCown v. International Harvester Co., 463 Pa. 13, 18-19, 342 A.2d 381, 383-84 (1975) (Pomeroy, J, concurring) (stressing risk-spreading rationale for holding that contributory negligence does not apply to products liability cases).

79. Duncan v. Cessna Aircraft Co., 665 S.W.2d 414, 422-28 (Tex. 1984) (abandoning assumption of risk, product misuse and failing to avoid damages in favor of single "comparative causation" concept that will proportionately reduce, but not preclude, the plaintiffs judgment). But see McCown v. International Harvester Co., $463 \mathrm{~Pa} .13,19,342$ A.2d 381, 384 (1975) (Pomeroy, J., concurring) (risk-spreading justifies denying manufacturers contributory negligence defense, but is outweighed by countervailing policy reasons in support of assumption of risk defense).

80. See Duncan, 665 S.W.2d 414. In addition, see the insurance effects of manufacturer liability for foreseeable consumer misuse, Hughes v. Magic Chef, Inc., 288 N.W.2d 542, 546 (Iowa 1980); 
status of the victim (as in actions brought by licensees and trespassers against property owners) ${ }_{j}^{81}$ and to restrict the effectiveness of statutes of limitation. ${ }^{82}$ At the same time, the theory has supported the affirmative extension of liability through the adoption of standards of strict liability, ${ }^{83}$ retrospective liability, ${ }^{84}$ and unreasonably dangerous per se, ${ }^{85}$ relaxation of causation requirements, ${ }^{86}$ and, more generally, through the nearuniversal acceptance of comparative negligence, which permits a jury to render judgments against defendants even if they are responsible only in some small proportion for a plaintiff's injury ${ }^{87}$

These legal changes have particularly affected insurers because courts have simultaneously expanded the scope of the insurance contract. Again, under the influence of enterprise liability theory, courts have adopted the maximization of insurance coverage as the principal interpretive objective in insurance contract disputes. ${ }^{88}$ Thus, courts have interpreted policy coverage provisions broadly and policy exclusions narrowly to achieve the compensation goal.

As a result of these doctrinal developments, both the range of defendants against whom a plaintiff might collect a judgment and the range of plaintiffs to whom a corporate defendant might ultimately be liable, have expanded. Courts have also expanded the range of losses for which compensation might be sought, chiefly by allowing increased recovery of emotional and other non-economic losses. ${ }^{89}$

General Motors Corp. v. Hopkins, 548 S.W.2d 344 (Tex. 1977), and despite intervening negligence, Huff v. White Motor Corp., 565 F.2d 104, 109-10 (7th Cir. 1977) (vehicle collision is foreseeable use).

81. E.g., Rowland v. Christian, 69 Cal. 2d 108, 443 P.2d 561, 70 Cal. Rptr. 97 (1968). For a broader discussion of these developments, see Prosskr \& KeEron on the LaW of ToRTs $\S 63$ (W. Keeton 5th ed. 1984).

82. The occurrence-manifestation disputes provide good examples. See, e.g., Keene Corp. v. Insurance Co. of N. $\Lambda \mathrm{m}$., 667 F.2d 1034 (D.C. Cir. 1981) (in addition to general liability policies in effect at time of asbestos inhalation, policies in effect at time of residence of asbestos in lung, and manifestation of asbestos-related disease cover liability of asbestos manufacturer to injured worker), cert. denied, 455 U.S. 1007 (1982). See also the invocation of the insurance rationale to resolve evidentiary issues against manufacturers in Cipollone v. Liggett Group, Giv. Action No. 83-2864 (D.N.J. Sept. $25,1986)$.

83. See Enterprise Liability, supra note 28 , at 496-519.

84. Barker v. Lull Eng'g Co., 20 Cal. 3d 413, 434, 573 P.2d 443, 457, 143 Cal. Rptr. 225 (1978) (fact that manufacturer took reasonable precautions to design safe product does not prevent imposition of strict liability upon hindsight judgment that product was unsafe); Beshada v. Johns-Manville Prods. Corp., 90 N.J. 191, 202-09, 447 A.2d 539, 545-49 (1982) (manufacturers liable for failure to warn of hazards unknowable at time of manufacture). But see Feldman v. Lederle Laboratories, 97 N.J. 429, 479 A.2d 374 (1984) (apparently limiting such liability to asbestos-like circumstances).

85. Halphen v. Johns-Manville Sales Corp., 484 So. 2d 110 (La. 1986).

86. See, e.g., Sindell v. Abbott Laboratories, 26 Cal. 3d 588, 607 P.2d 924, 163 Cal. Rptr. 132 (creating "market share" liability), cert. denied, 449 U.S. 912 (1980).

87. E.g., Daly v. General Motors Corp., 20 Cal. 3d 725, 575 P.2d 1162, 144 Cal. Rptr. 380 (1978).

88. See generally K. Abraham, Disiributing; Risk (1986); Keene, supra note 82, at 1041.

89. See, e.g., Hagerty v. L \& L Marine Servs., 788 F.2d 315, 317-18 (5th Cir. 1986) (damages 
Understanding the insurance crisis requires that the economic effects of expanded liability be analyzed precisely. Putting aside administrative costs, a legal rule or agency regulation can have two principal economic effects: (1) it can influence investments in loss prevention to affect the accident rate; and (2) it can influence the provision of insurance for losses not prevented. ${ }^{90}$ These two effects, prevention and insurance, are the only important economic consequences of any legal or regulatory policy. It is irrelevant which goals a court, a regulatory agency, or society is trying to achieve. It is unimportant if the motivation for a legal policy is some moral imperative, some vague or specific sense of justice, or personal or pecuniary advantage. The only important economic effects that any legal policy can have are effects on levels of investments in prevention of losses and of insurance for losses not prevented.

It is well accepted that the optimal level of accident prevention will be attained if incentives are created for both the provider and consumer to make additional safety investments up to the point at which the marginal costs of such investments equal their marginal benefits. ${ }^{91}$ Regardless of context, the accident prevention question is whether it was cost-effective for the provider or for the consumer to have made greater investments to prevent the loss. If the finder of fact determines that neither party could have prevented the loss in a cost-effective manner, then the resolution of the dispute in favor of the plaintiff or the defendant serves only to determine which party is to be the insurer for the loss, that is, where the loss should lie, given that the loss could not have been efficiently prevented.

Some courts and agencies appear to believe that increasing the obligation of providers to compensate victims will always increase these providers' investments in safety. Where damage measures are compensatory, however, there is a very definite ceiling to the accident prevention investments that any provider will make. ${ }^{22}$ Providers will make investments to reduce the accident rate only to the extent that such investments are costeffective-that is, that the marginal costs of preventive investments are less than the marginal gain in expected accident cost reduction. Beyond that

for fear of (ancer recoverable by seaman under Jones $\Lambda \mathrm{ct}$ ).

90. Legal rules also affect the levels of injurer and victim activity. The economic dimension of such a shif,, however, is only perceptible if information is available-as it seldom, if ever, is-about the shapes of injurer and victim utility functions, including demand and supply conditions for injurer and victim activities, respectively. In my view, few practical benefits can be obtained by considering the abstract effects of internalizing costs to affect activity levels. See G. Priest, Internalizing Costs (1987) (unpublished manuscript on file with author).

91. See generally R. Posnte, Ec:onomic: ANAi.ysis of Law 147-52 (3d ed. 1986).

92. Awards in excess of compensatory damages, such as punitive damages, can in theory lead to either an increase or a reduction in aggregate safety levels. See Priest, Punitive Damages and Enterprise Liability, 56 S. Cal.. L. Rrv. 123, 128-32 (1982); G. Priest \& J. Donohue, The Determinants of the Accident Rate (1987) (unpublished manuscript on file with author). 
point, it is less costly to pay damage claims or judgments than to prevent accidents from occurring. Thus, extending liability beyond that point will not affect the level of safety investments.

There are insurance implications, however, of every liability decision. If a liability standard were set only to require cost-effective preventive investments by a provider, some losses would still occur. ${ }^{93}$ Victims would bear these losses, and thus would bear the obligation to obtain insurance for them through some first-party insurance mechanism. In contrast, if a provider were held liable for losses which the provider could not costeffectively have prevented, the provider would bear the obligation to provide insurance. Either through self-insurance or some form of third-party insurance, the provider insures victims for losses that cannot efficiently be prevented.

The economic effects of steadily increasing provider liability thus are quite simple in structure. A liability rule can compel providers of products and services to make investments that reduce the accident rate up to the level of optimal (cost-effective) investments. ${ }^{94}$ After providers have invested optimally in prevention, however, any further assignment of liability affects only the provision of insurance. More extensive provider liability will generate more extensive provider insurance and nothing more.

The expansion of liability under modern tort law has obviously increased the provision of provider insurance. Any standard beyond a bare cost-benefit test (often identified with negligence) ${ }^{95}$ will provide an insurance effect. Courts, of course, have extended liability far beyond the simple cost-benefit standard. Thus, modern tort law compels a very substantial level of provider insurance.

More precisely, modern tort law has broadly shifted the insurance obligation from first-party insurance to third-party or self-insurance by providers. Even a bare-bones cost-benefit standard has insurance consequences: Such a standard creates an obligation of potential victims to obtain market insurance or to self-insure for unpreventable losses. Modern tort law has shifted that obligation to providers, requiring providers either to obtain third-party market insurance or to self-insure for the losses suffered by consumers of their products or services. The expansion of tort liability since the mid-1960's has expanded the range of contexts in which provider insurance must be offered. Courts understand this point

93. Injurers and victims are likely to make errors in choosing optimal forms of accident prevention and some accidents are not worth preventing.

94. Again, this analysis puts aside considerations of greater than compensatory damages. See supra note 92.

95. See Posner, A Theory of Negligence, 1 J. Licial. Srud. 29 (1972). I am very skeptical that the negligence standard, as it is applied by courts and juries, closely resembles an economically efficient cost-benefit standard. 
perfectly. Much of the modern extension of tort liability has been expressly justified by the salutary insurance consequences that are supposed to result. ${ }^{86}$ Thus it is a paradox that the modern regime somehow has led to the reduction of insurance availability. The next Section examines more closely the operation of insurance markets in an attempt to resolve the paradox.

\section{How Insurance Operates}

This Section discusses some straightforward principles of the operation of insurance markets. It describes how insurance benefits consumers and thus what types of losses consumers will want to insure, the role of insurance companies in creating viable insurance pools, the determinants of insurance premiums, the different economic effects of differently defined risk pools, the limitations on the survivability of such pools, and the necessary conditions for expanding the availability of insurance within the society. The insurance principles discussed here are quite general. They apply to all insurance contexts and are not specific to the American economy. Nevertheless, they provide a basis for understanding the specific ways in which recent changes in American tort law have contributed to our current insurance crisis.

Insurance provides a method for individuals to equalize the amount of money available to them over diverse states of the world-states in which losses occur and those in which there are no losses. Most commonly, it is a method of equalizing money available over time. The insured pays a premium, reducing his or her current wealth, in return for the insurer's agreement to pay some monetary amount to the insured should a loss occur. Insurance is different from savings because the amount paid out by the insurer is not (and may never be) absolutely equal to the amount paid in by the insured, obviously, for example, when the loss occurs in an early insurance period. ${ }^{97}$

The insurance function, instead, requires that the losses have some probabilistic character. If it were certain that a person would suffer a particular loss in some particular period, insurance would be without purpose; the problem would be one of either accumulating savings before the loss occurs or trying to restore the previous economic position after the loss is suffered. Insurance, in contrast, requires that the loss be probabilis-

\footnotetext{
96. See cases cited supra notes 76-89.

97. $\Lambda \mathrm{s}$ an example of the difference between savings and life insurance, a family that saves a certain amount each year for use after a wage earner's death can draw, after that event, on the accumulated savings amount (plus earned interest). In contrast, a family that purchases life insurance will receive much more in dollar benefits than it paid in premiums if the death occurs early relative to expected mortality, and much less in benefits than premiums paid if death occurs late.
} 
tic, either as to whether or not it occurs at all (for example, whether one's house burns down) or as to when the loss occurs (for example, whether one dies before or after full life expectancy). The insurance premium is set equal to the value of the expected loss for the period, plus a share of the costs of administering the system, called loading costs.

The insurer's function is to aggregate uncorrelated (that is, independent) risks and segregate these risks into separate risk pools. The uncorrelated character of the risks distinguishes insurance from savings. Risks that are uncorrelated are risks of which the incidence of loss is spread out, either in terms of time or in terms of the individuals suffering the loss. As long as the risks of pool members are uncorrelated, that is, statistically independent, ${ }^{98}$ the insurer can accumulate small premiums from each insured and still have funds sufficient in any period to pay those losses that actually occur. In contrast, if risks were highly correlated, there would be no advantage to aggregating them. Thus, losses from nuclear war are uninsurable.

The insurer's aggregation function derives from operation of the law of large numbers-the empirical phenomenon according to which the probability density function of average loss tends to become concentrated around the mean as the sample number increases. ${ }^{89}$ Applied to insurance, the law of large numbers means that as one increases the number of insured persons possessing independent and identically-valued risks, one increases the accuracy of prediction of expected loss for each individual. As should be obvious, increasing predictive accuracy reduces the effective risk faced by the insurer, since the level of aggregate risk is a function of the variance of expected outcomes. ${ }^{100}$ Described more precisely, then, the role of the insurer is to identify risks that are independent (uncorrelated) and equally valued, and to aggregate them in order to reduce the total risk of the set. ${ }^{101}$

This general statement of the insurance purpose refers to risks being equally valued. Of course, no two individuals bring exactly the same risk level into an insurance pool. Nevertheless, it is crucial to the insurance enterprise to segregate uncorrelated risks, as much as possible, into separate, narrowly-defined risk pools in order to control adverse selection. Ad-

98. Statistical independence is when the occurrence of one event does not alter the probability of the other. For example, repeated flips of a fair coin are statistically independent events; even if the last 100 flips have all come up heads, there is still a $50 \%$ chance of tossing heads next time.

99. See Marshall, Insurance Theory: Reserves Versus Mutuality, 12 Econ. InquiRY 476 (1974).

100. For a definition of variance, see infra note 103 .

101. The insurer may also monitor the risks of the insured's activity to persuade the insured to reduce its level of risk and provide a claims adjustment service. The relative effectiveness of insurers serving these functions is not likely to be different before and after the recent crisis. Thus, I do not regard them as central to an explanation of the crisis, even though they may be very important benefits provided by market insurance. 
verse selection is commonly described as the tendency of persons with relatively greater exposure to risk to seek insurance protection. ${ }^{102}$ But the problem is broader. Adverse selection is a problem central to every insurance context, and it dominates the insurance function. An insurer must collect into a risk pool individuals with a sufficiently narrow range of exposure to risk for the insurance to remain financially attractive to each member of the pool. The insurance premium for the pool must be set according to the average level of risk brought to the pool. The wider the range between high-risk and low-risk pool members, the greater the difference between the average risk and the risk of low-risk members. Lowrisk members pay a premium that, because it is based on an average which includes high-risk members, is more than they would have to pay if they could be segregated into a risk pool of their own.

If the disparity between the premium and the risks added by low-risk members becomes too substantial, low-risk members may drop out of the pool because they find alternative means of protection cheaper than market insurance. This is the most difficult problem faced by any insurance pool. Most individuals may be risk-averse; that is, they may be willing to pay an amount somewhat greater than their actual expected loss in order to avoid suffering the loss. But risk aversion is never infinite, and the costs of alternatives to market insurance, such as investments to reduce the likelihood of the loss or to reduce financial exposure to the loss, are never infinite. Obviously, as low-risk members drop out, a pool will consist more predominantly of high-risk members, requiring the premium to be raised and placing greater pressure on the remaining low-risk members of the pool.

Narrowing the range of risks within a pool increases the attractiveness of insurance to low-risk members. Obviously, as mentioned above, the less the average risk brought to the pool by other members exceeds the risk brought by a given insured, the less the premium for the pool will exceed the given insured's expected loss, and the more advantageous market insurance will appear to the insured.

The range of risks brought to an insurance pool also affects the premium for the pool in a second way, beyond its influence on average risk. Risk pools may differ in degrees of variance (coefficients of variation), even if the average risks of the pools are the same. ${ }^{103}$ An insurer, however,

102. Dininberc; Eil.ers, Hoffman, Klinf, Mklone \& Snider, Risk and Insurance 191-92 (1964); see also Epstein, Products Liability as an Insurance Market, 14 J. Legal Stud. $645,650-52$ (1985) (discussing adverse selection and the failure of modern products liability law to control it).

103. The variance of a distribution is the square of the sum of the differences between each observation and the mean: variance $=\sigma^{2}=\Sigma\left(x_{i}-\bar{x}\right)^{2}$, where $\bar{x}=$ the mean of the distribution and $x_{i}$, each observation. 
cannot be indifferent to the degree of variance of a risk pool. A pool incorporating greater variance of the risk distribution is a pool for which the potential range of aggregate losses is greater-even if the average expected loss is the same.

Essentially, an insurer is an agent for the diversification of risks. ${ }^{104}$ The insurer diversifies risks by accumulating insurance contracts for uncorrelated risks, and then by investing premiums in common stock or other assets whose investment risks are uncorrelated, or by reinsuring (hiring other insurers to perform the diversification function). Diversification investments are costly. As with more typical production functions, the greater the risks that must be diversified, the more costly the diversification investments become. Thus, as the variance of a risk pool increases, the cost of insuring the pool increases, and the premium increases. ${ }^{105}$ Insurers are often accused, in obvious irony, of being extremely risk-averse; insurers as individuals are said frequently to hate taking risks. Even if accurately described, such personal characteristics are not clearly relevant to the problem. The point is that the costs of diversification to an insurer (or to anyone else) increase as the risks that must be diversified increase.

Thus, it is essential to the insurance function to define risk pools as narrowly as possible so that the premium for the pool is as close as possible to the expected loss of low-risk members of the pool. Narrowing risk pools reduces the adverse selection problem by reducing the incentives for low-risk members to drop out of insurance pools. If differences among the risk levels of pool members are too broad, the pool will unravel as lowrisk members successively drop out. ${ }^{106}$ The principal reason risks are uninsurable is that insurers are unable to narrow the assortment of risks within a pool.

One can now see the similarity in effect of the aggregation and segregation functions of the insurer: both reduce risk variance and thus serve to reduce the costs of insurance. By identifying independent risks and aggregating them into a risk pool, the insurer increases predictive accuracy by exploiting the law of large numbers. Increasing predictive accuracy reduces the risk level of the pool, even if it does not affect in any way the frequency of losses that actually occur. ${ }^{107}$ In contrast, if the risks faced by

104. Again, I do not mean to minimize the productive efficiencies achieved by insurer monitoring of risky activities or by claims adjustment. See supra note 101 .

105. For other formulations of this point, see Cummins, Insurer's Risk: A Restatement, $41 \mathrm{~J}$. RIsk \& INs. 147 (1974); Venezian, Insurer Capital Needs Under Parameter Uncertainty, 42 J. RISK \& INS. 19 (1975).

106. Akerlof, The Market for "Lemons": Quality Uncertainty and the Market Mechanism, 84 Q.J. EcoN. 488 (1970). The unraveling process is described more fully and illustrated infra at text accompanying notes 216-26.

107. The mutuality principle for insurance, which departs in some ways from the pooling effects of the law of large numbers, must be distinguished. See infra text accompanying notes 232-34. 
members of the pool are not independent, then the law of large numbers does not apply. Aggregating such risks would be unproductive because the reserves the insurer would have to maintain would equal or, perhaps, exceed the reserves individuals would have to maintain if uninsured. ${ }^{108}$ Again, this is why society-wide calamities, such as nuclear war, are uninsurable.

Segregation of risks into separate pools according to levels of expected risk serves a complementary function. Like the law of large numbers, segregation according to risk level concentrates a probability density function of loss around its mean. It improves an insurer's ability to predict expected loss, making possible greater predictive accuracy even with fewer insureds in the pool. Thus, segregation reduces both pool riskiness and insurance costs. In addition, segregation into narrow risk pools ${ }^{\mathbf{1 0 9}}$ reduces adverse selection, because it makes insurance more attractive to the lowrisk members of the risk pool.

It is commonly believed that there is a tension between the advantages of segregating insureds into particularized risk categories and the advantages of spreading risks broadly over some set of the population. Many seem to think that the more individualized the risk calculation, the lower the extent of risk spreading. ${ }^{110}$ This view, however, derives from an incomplete understanding of the concept of risk spreading. Putting aside distributional preferences, ${ }^{111}$ risk spreading is achieved by the aggregation of independent risks. If risks are uncorrelated and probabilistic in nature (which is what is meant by their being independent), then their aggregation is all that is necessary to achieve spreading. Insureds gain from such transactions because aggregation of the risks lowers the effective risk to each member of the pool. Even if the premium charged to each member of the pool is slightly greater than true expected loss, it is still less than the cost of self-insurance, because self-insurance necessarily requires taking into account a greater range of possible outcomes. Risk-spreading efficiency should be defined in terms of reduction in the coefficient of variation of the probability density function of average loss. Thus, if risk pools have been carefully segregated, risks can be spread efficiently over very small numbers of the population.

108. Marshall, supra note 99 , at 477 ; see infra note 111 and accompanying text. This is also the best explanation for the terms of the typical force majeure clause in contract law.

109. I hope it is obvious that by "narrow" I mean with small variance or concentrated around the mean as opposed to small in number.

110. See generally James, Accident Liability Reconsidered: The Impact of Liability Insurance, 57 YAL.F. L.J. 549 (1948).

111. The term "risk spreading" is sometimes used to describe shifting the costs of bearing risks away from parties that generate them as, for example, assigned risk pools that shift the costs generated by more risky drivers to the less risky. I am using the term, instead, to refer to spreading that serves to reduce effective risk. 
Much of the insurance business involves literally individual assessment and pricing of risks. The insurance I have described to this point is called "class underwriting." "Special risk underwriting," in contrast-which is more predominant in some of the commercial casualty lines affected by the insurance crisis-involves risk estimates by the insurer on an individual risk-by-risk basis, with the premium (rather than a rate) set with the particular characteristics of the insured in mind.

Special risk underwriting, however, is only a particular case of the aggregation and risk spreading described above. There is no insurance advantage to underwriting only a single special risk, or even a set of special risks which are highly correlated, because the insurer would have no comparative advantage to the insured. Instead, an insurer will achieve the risk spreading and predictive accuracy objectives by underwriting a group of special risks for which risks are mutually independent, or a group whose risks are independent of other risks underwritten by the insurer. The insurer will bring to bear information that it has gathered and its experience in estimating the expected loss of each special risk. This estimation, obviously, will incorporate some variance in outcomes which will require the premium to be set above the mean of the probability density function of loss. As long as the risks brought by the insureds are independent, however, the insurer can realize advantages from aggregation that resemble the advantage that the operation of the law of large numbers gives to class underwriting.

As an example, imagine an insurer asked to write a products liability policy for a single manufacturer of a unique product. Putting aside other insurer skills, the insurer has no comparative advantage to a single manufacturer in establishing reserves against future expected losses.112 If the insurer, however, can also write products liability policies for other manufacturers of unique products, the insurer can create an effect similar to that of the law of large numbers. As long as the risks of the individual manufacturers are independent, the level of total risk will be less than the sum of the individual risks. Thus, the risk that all products will be designed defectively is less than the sum of the risks that any one product will be designed defectively. If the risks faced by the insurer, however, are highly correlated and not independent-such as the "socio-legal risk" that the legal standard for proving defective design will be relaxed-the benefits from aggregation are defeated. Total risk will equal the sum of the individual risks, ${ }^{113}$ and the insurer has no comparative advantage to the insureds themselves.

112. Irrelevant to this point, for example, are insurer productive efficiencies in risk monitoring, claims servicing or portfolio selection.

113. It may exceed the sum, especially, if the total risks threaten to swamp the total assets of the 
It is a well-established implication of this approach that the more narrowly risk pools can be defined, the more broadly insurance can be offered in the society. ${ }^{14} \mathrm{~A}$ legislature or court that wanted to maximize the availability of insurance within the society would adopt policies that facilitated the segregation of risks into the narrowest possible pools. Competition among insurers serves this objective. Insurers try to lure an insured away from competitors by offering membership in a pool for which the premium is closer to the insured's expected loss, because of the more discrete definition of the pool. In essence, the insurers are competing over the relatively low-risk insureds of any risk pool, who are likely to select that insurer most precisely able to price the risk the insured brings to the pool. Such competition increases total insurance availability. Unfortunately, much of modern insurance regulation is designed to thwart such efforts. ${ }^{115}$ As we shall see, much of modern tort law (and, incidentally, much of the modern judicial approach toward the interpretation of insurance contracts) also impairs the ability of insurers to define narrow risk pools in order to extend insurance availability.

Most of us are familiar with a wide variety of methods insurers employ in first-party insurance contexts to narrow risk pools. Distinctions in casualty policies, for example, among homes with or without smoke alarms or homes closer to or farther from fire hydrants, reduce differences in risk among insureds within a pool. The different premiums that auto insurers charge to teen-age drivers or to owners of cars with collision-resistant bumpers relate, obviously, to the risk that each insured brings to the pool. All forms of experience rating serve the same end. Distinguishing in these various ways among insureds increases the availability of insurance because it makes market insurance more attractive to relatively low-risk individuals. ${ }^{116}$

An additional way that risk pools are segregated in virtually every firstparty context is by the level of insurance protection desired. Insurers, obviously, charge different premiums to those who want larger amounts of life insurance coverage than to those who want smaller amounts. Similarly, the fire or casualty insurance premium is different for those that live in expensive houses than for those that live more modestly. It is clearer in

insurer and there is a deadweight loss to reorganization through bankruptcy.

114. See Rothschild \& Stiglitz, Equilibrium in Competitive Insurance Markets: An Essay on the Economics of Imperfect Information, 90 Q.J. EcoN. 629 (1976).

115. In this respect, the Justice Department Working Group's conclusion that state insurance regulation has not had much effect on the current insurance crisis, DOJ REPORT, supra note 24, at 59,80 , is likely to be a serious underestimation of the problem.

116. For a discussion of methods of narrowing risk pools in the context of consumer product warranty insurance/repair contracts, see Priest, A Theory of the Consumer Product Warranty, 90 YAl.t. L.J. 1297 (1981). 
these contexts, perhaps, to see how narrowing risk pools increases the availability of insurance. If all homeowners were charged the same casualty premium regardless of home value, or if, say, all apartment dwellers were charged the same premium for contents coverage without regard to furniture value, the attractiveness of market insurance would decline. Those possessing less expensive homes or furniture-the low-risk members of the pool-would have to be exceptionally risk-averse to find the uniform premium worth its cost. Such individuals would be more likely to purchase market insurance if the casualty premium corresponded more closely to the level of risk they brought to the pool.

This example also shows how constraints on risk segregation redistribute wealth. A single uniform premium for apartment contents coverage, set equal to average expected loss of all apartment dwellers, will be lower than the expected losses of those who possess antiques, and higher than the expected losses of those who possess hand-me-downs. Similarly, a uniform premium for an employment disability policy will be lower than the expected loss to high-income workers, and higher than the expected loss to low-income workers. Where the risk level is related to wealth or income, a uniform premium compels those with less wealth or income to subsidize those with more. In such contexts, individuals with lower levels of wealth and income will prefer to drop out of the insurance market, if they are able to do so, in order to preserve the limited resources they have. ${ }^{117}$

I mentioned earlier that insurance provides a method to equalize available amounts of money over states of the world. More specifically, insurance is a method of equalizing the utility gained from money over states of the world. ${ }^{118}$ The purpose of insurance is tied to the use of money because insurers can provide us only with dollars should a loss occur. Individuals, as a consequence, do not voluntarily insure for non-pecuniary losses. Parents, for example, do not typically purchase insurance on the life of a minor child, ${ }^{119}$ not because the parents would not suffer severely if the child were to die, but because the child's death will not affect the flow of money into the family. More precisely, there is no advantage to a family in suffering a financial sacrifice by paying insurance premiums while the child is alive in order to increase the family budget after the child dies. In

117. Of course, there is always some level of redistribution in any risk pool from low-risk insureds to high-risk insureds because of the impossibility of perfect segregation. Insurance will still remain attractive to the low-risk insured if the extent of redistribution is less than the insured's relative risk aversion. Obviously, the more closely the premium for the risk pool approximates the risk brought by the low-risk insured, the more attractive market insurance becomes.

118. See Zeckhauser, Coverage for Catastrophic Illness, 21 Pub. Pol.'Y 149 (1973), for interesting variations on this point.

119. I am discussing here term insurance, rather than whole life insurance. Because whole life incorporates a predominant savings component, decisions about its purchase are different. 
contrast, if instead of a minor, the child is an adult providing financial support to the parents, the concerns are reversed. It may very well make sense to reduce the monetary amounts available for use today (to the parents or to the child purchasing life or disability insurance on the child) in order to guarantee a steady flow of resources later if the child-provider were to die.

A similar reason might explain why we never observe individuals purchasing insurance for pain and suffering or other emotional losses. However severe the pain, a larger bank account is an imperfect anesthetic. As a consequence, there is no market for pain and suffering insurance in any society in the world. Indeed, if the pain is especially severe, individuals may prefer a form of reverse or anti-insurance: more assets available to enjoy before the accident than after. Of course, there are very limited situations in which anti-insurance of this nature can be arranged. ${ }^{\mathbf{2 0}}$

The lack of consumer demand for insurance for pain and suffering losses is certainly also a consequence of adverse selection problems. Individuals may differ substantially in the level of pain and suffering that they experience or can tolerate. If so, offering coverage for pain and suffering will increase the variance of risks brought to an insurance pool. ${ }^{121}$ As before, if the variance in expected risks is sufficiently great, the risks will be uninsurable because the low-risk members will successively drop out of the pool.

Pain and suffering may also involve moral hazard, although the problem of moral hazard extends far more broadly. Moral hazard refers to the effect of the existence of insurance itself on the level of insurance claims made by the insured. Moral hazard can occur either ex ante or ex post the occurrence of the loss. Ex ante moral hazard is the reduction in precautions taken by the insured to prevent the loss, because of the existence of insurance. Ex post moral hazard is the increase in claims against the insurance policy beyond the services the claimant would purchase if not insured. In the context of medical insurance, for example, ex post moral hazard includes excessive (at full-price) visits to doctors, longer hospital stays, and more elaborate and expensive methods of treatment. In this context, a person who might, ex ante, choose one level of care, may ex post, choose more care, because the costs of the care are paid by the insurer. Full insurance reduces the price of future purchases of medical care

120. Zeckhauser, supra note 118 , at 157 , suggests an old folks' home whose inhabitants are without descendants, and spend every resource they have while alive, but bequeath the assets they retained as necessary during life to the other inhabitants of the home for current enjoyment.

121. Similar problems of measurement also explain why life insurance (unlike health or disability coverage) is never offered subject to subsequent valuation, but rather is offered in prespecified amounts. 
to zero, and so a person is likely to choose a greater level of care than he or she would choose if charged for the care at marginal cost. ${ }^{122}$

Moral hazard, in part, is a particular source of the adverse selection problem. Where insureds, ex post, can affect the level of claimed losses, the variance in expected risks increases. Those individuals who are less likely to gain from exaggerated visits to doctors or from more extensive hospitalization will drop out of the pool if full coverage is offered. ${ }^{123}$

For these reasons, market insurance universally incorporates deductibles and coinsurance where the extent of the loss can be influenced by insureds' ex ante or ex post decisions. A deductible is a condition in an insurance contract that requires an insured filing an insurance claim to pay a fixed sum unrelated to the magnitude of the claim. Coinsurance requires the insured to pay some fraction of the amount of each claim. ${ }^{\mathbf{1 2 4}}$ Deductibles and coinsurance reduce indifference to preventive investments, and they reduce the incentive to consume what, from an ex ante view, are excessive levels of the service for which insurance has been purchased. They reduce differences in risks brought to insurance pools.

The discussion to this point has addressed only first-party insurance. Tort law, of course, provides insurance through a third-party mechanism: the insurer pays money to the victim through the medium of the product or service provider who purchases the insurance policy. Although thirdparty institutional arrangements are somewhat more complex than firstparty arrangements, the determinants of the insurance function are the same.

In third-party insurance, there are two sets of risk pools. Consumers of products or services comprise one set of risk pools. To consumers, the insurance policy and the premium are tied to the sale of the product. It is advantageous to define risk pools narrowly for consumers in third-party contexts for exactly the same reasons that it is advantageous to define risk pools narrowly in typical first-party insurance contexts. Defining consumer risk pools narrowly increases product sales, because the premium added to the price of the product more closely approximates the consumer's expected loss.

Manufacturers, for example, will attempt to segregate consumers into

122. In fact, consumers as a group do pay ex ante for the excessive care demanded under a nodeductible policy, because the insurer exacts higher premiums to cover the higher amount of claims. Ex post, however, any individual insured faced with the choice of levels of medical care has much more to gain by using too much care than he or she loses in higher premiums. See Pauly, The Economics of Moral Hazard: Comment, 58 AM. EcoN. REv. 531, 533-35 (1968).

123. Controlling moral hazard, of course, is likely to also include some degree of hands-tying, its more typical explanation. See id. at 535.

124. For example, Blue Cross-Blue Shield typically pays only $80 \%$ of major medical expenses. The insured coinsures the other $20 \%$. 
risk pools by product design and by advertising and marketing techniques. A chain-saw manufacturer, for example, may design one model appropriate for industrial use and a second model appropriate for occasional gathering of firewood. Of course, such design differences may also be related to different consumer preferences for product features-in this example, features related to safety. But the point is that, if the demand for chain saw injury insurance coverage differs between the professional and the weekender, both consumers and the manufacturer will gain if the manufacturer can design products that differentiate the two markets. In this example, market differentiation would reduce one very broad risk pool into two more narrow risk pools. Narrowing the pools allows the manufacturer to charge different insurance premiums to the two markets and to increase product sales.

Similarly, the accident insurance premium added to the price of an airline ticket from the United States to Europe will be greater on, say, the Concorde than on low-budget or charter lines. ${ }^{125}$ The risk of an accident among the various airlines may be the same, but the accident payout risks brought into the pool by passengers on the Concorde are likely to be much greater than the risks brought by charter passengers, if only because of their greater expected future income. The third-party insurance premium must be adjusted in response. In this respect, the qualitative differences between the Concorde and the charters in terms of accident insurance are no different than qualitative differences in meals, time of transit, or other amenities. Indeed, much of the attraction of the charters derives exactly from the ability of these firms to narrow the pool of consumers of their product. Those passengers who travel on low-fare flights are those who prefer or are willing to tolerate lower levels of amenities in return for a lower ticket price.

The second set of risk pools within third-party insurance contexts includes the service and product providers themselves. Providers of products and services purchase market insurance for the same purposes as any first-party insured: to equalize monetary returns over time in the face of some probabilistic chance of loss. Providers will choose market insurance if its costs are lower than the costs of alternatives. ${ }^{126}$

125. I ignore here the effects of the Geneva and proposed Montreal Conventions limiting damages for international (but not United States originating) air travel. 47 Stat. 2021 (1929). These Conventions reduce differences in risk pools by limiting damages owed by the airlines to victims of air crashes.

126. The most common and best-known alternative to market insurance is self-insurance-the maintenance of reserves adequate to meet expected losses and the threat of bankrupty if these reserves prove too low. See infra notes 190-93 and accompanying text. Self-insurance has been popularly called "going bare." $\Lambda$ recently popular alternative to market insurance, that is something of a hybrid of going bare and buying standard insurance, is insuring through industry mutuals. See infra text accompanying notes $227-42$. 
The costs a provider faces by deciding not to purchase insurance depend upon diversification within the provider firm or the provider's ability to diversify risk by other means. ${ }^{127}$ As suggested above, marketing different models of a product is a form of diversification, if the risks of loss attending sales of the respective models are uncorrelated. Of course, organization in the conglomerate form or investing retained earnings in diversified assets are other ways in which providers can self-insure. ${ }^{128}$

Insurance companies, however, can (and do) compete for the custom of providers by trying to define narrow risk pools that make market insurance more attractive than self-insurance alternatives. Insurers attempt to aggregate within a pool a set of providers whose risks are uncorrelated, and will set individual premiums for the firms according to the risk each brings to the pool. The insurer's diversification of risk, again, can be achieved either by aggregating a very disparate pool, by holding other assets whose riskiness is uncorrelated, or by reinsuring-hiring another insurer to provide meta-diversification.

These simple insurance principles seem very general, but they provide an explanation for the insurance crisis we are currently observing. The next Section attempts to apply these principles to the changes in tort law discussed in Section II, in order to predict the effects of modern law on insurance availability.

\section{How Contemporary Tort Law Affects Insurance MARKETS}

As discussed earlier, ${ }^{128}$ over the past two decades, courts have expanded corporate liability in order to provide compensation insurance to injured persons through tort recoveries. This Section illustrates how the expansion of corporate liability has progressively undermined the insurance function by increasing the variance (coefficient of variation) of existing insurance risk pools. As described in the preceding Section, increasing the variance of a risk pool endangers the pool because it increases the likelihood that the pool will unravel as low-risk members drop out, either by selfinsuring or by ceasing to engage in the potentially injury-related activity. This Section shows these effects in both consumer and provider risk pools. Thus, it shows that contemporary tort law has restricted rather than expanded insurance availability. The parties that have been most adversely

127. The purchase of market insurance by a firm, thus, is likely to involve more complicated questions of corporate finance. See Mayers \& Smith, On the Corporate Demand for Insurance, $55 \mathrm{~J}$. Bus. 281 (1982); see also infra text accompanying note 164.

128. For a discussion of the corporate demand for insurance, see infra text accompanying notes 159-64.

129. See supra Section II. 


\section{The Current Insurance Crisis}

affected are the low-income and poor who, in terms of tort recoveries, are the low-risk members of the consuming population.

It is helpful at the outset to describe forms of expanding liability that will not affect insurance markets. The Justice Department has argued that the insurance crisis is the result of increases in the level of damage judgments over the past ten years, emphasizing increases in average tort judgments in medical malpractice and products liability cases, in particular. ${ }^{130}$ Earlier, I challenged the Department's empirical substantiation of its claim (as have many others), ${ }^{131}$ but a stronger criticism should be made. Other things equal, a scalar (proportionately equal) increase in the level of tort judgments and settlements will not affect the degree of insurability of any risk. A scalar increase in tort payouts, other things equal, does not affect the marginal benefit of insurance to any insured because it will not change the ratio of the premium to an insured's expected loss. ${ }^{\mathbf{1 3 2}}$ The premium set equal to the average risk brought to the pool will increase by exactly the same proportion as will the expected loss to the insured. ${ }^{133}$

Of course, modern tort law has changed in dimensions beyond the average damage judgment. I have described how modern tort law has expanded the range of plaintiffs to whom corporate enterprises are liable, the range of provider defendants against whom injured persons may bring suit, and the range of activities for which corporate enterprises have become subject to liability, ${ }^{134}$ changes which, obviously, expand commercial liability risk pools. The Justice Department, in addition, has suggested that increases in tort filings and in million dollar judgments have contributed to the crisis. ${ }^{135}$ I believe that these developments, in fact, have undermined commercial casualty insurance markets. But the exact mechanism that generates the effect is not immediately obvious. As a consequence, simple proposals, such as those of the Justice Department, to no more than retrench corporate liability are not immediately compelling. Increased corporate liability may surely increase corporate insurance costs, but why does it lead to a breakdown of the insurance function?

The question is especially puzzling because of the curious empirical context of the recent crisis. Two phenomena, in particular, are important

130. DOJ RripoR'r, supra note 24 , at 49,52 .

131. See supra text accompanying notes 65-71.

132. I am grateful to Ralph $\Lambda$. Winter, Armen Alchian, and Jack Carr for their comments on this point.

133. Ralph $\Lambda$. Winter has shown that insureds with relative risk aversion indices greater than one will be more likely to stay in than drop out of risk pools. R. Winter, Note on the Effect of Scalar Changes on Adverse Selection (1986) (unpublished manuscript on file with author).

134. See supra Section II.

135. DOJ RFPORT, supra note 24, at 35-42, 45-52. 
here. First, to repeat, there is no evidence of increase in the rate or severity of accidents for the principal set of activities affected by the crisis. Of course, in recent years some products have been newly discovered to be harmful (for example, the Dalkon Shield), generating substantial liability. But the insurance crisis has not been dominated by products of this nature; there have been no claims of previously unknown toxic damage from diving boards or slides in public parks.

Moreover, the extension of tort liability on insurance grounds has not generated totally new insurance coverage. Today, the vast majority of Americans possess health, disability, and life insurance coverage, either through private first-party sources or through government supported Medicaid, Medicare, Veterans' Benefits, and the like. ${ }^{136}$ Here, too, there are exceptions: chiefly occasional workers, such as migrant laborers, actors, artists; and the marginally poor, those who remain above the social service qualifying level while healthy and injured, but who are likely to qualify for social service "insurance" after they suffer an injury. ${ }^{137}$ Yet, again, no one claims that the insurance crisis has been generated by tort recoveries of occasional workers and the marginally poor. These individuals consume less and thus are less likely to be involved in product- or service-related injuries. More importantly, because these individuals have low levels of both current and prospective income, the damage judgments they recover are typically insubstantial. It follows that both past increases in tort judgments and expected future increases in tort judgments derive, in the largest part, from the claims of individuals already possessing firstparty insurance coverage.

These facts redefine the issue to be analyzed. If there has been no increase in the accident rate and if the largest majority of tort law claimants already possess first-party insurance, then the expansion of corporate legal liability has chiefly shifted coverage from (private and government) firstparty sources to corporate defendant third-party sources. The question, then, is why the shift from first- to third-party insurance sources has led to a breakdown in insurance markets?

I believe that there are very clear insurance reasons why the shift towards third-party coverage has undermined the commercial casualty insurance industry, generating the crisis. In comparison to first-party insurance, third-party tort law insurance provides coverage in excessive amounts, in a manner that substantially restricts risk segregation, and at

136. See G. Priest, Compensation Systems and Tort Law: A Preliminary Comparative Approach, (Program in Civil Liability Working Paper No. 50, Yale Law School, Oct. 1986), in Risk, Compensa'ion \& Liabil.try: The Polic:y Chotcrs (1986); see also Srin. Subcomm. on the Agrd, 99th Conci, 2n Sriss. Working; Paper No. 1: A Profil.t of Heal:th Benffits and the Uninsurfid (Subcomm. Print Oct. 17, 1986).

137. SkN. SUBComm. ON THE A(GE), supra note 136. 
costs that far exceed the costs of first-party insurance. For both consumer and provider risk pools, these differences will increase the correlation of risks within existing pools and, as a consequence, increase the extent of adverse selection, leading to the breakdown of the pools.

\section{A. Why Consumer Risk Pools Have Unraveled}

Provider tort law insurance coverage differs substantially from firstparty insurance coverage. One of the objectives of the tort system is to create incentives for appropriate investments in preventing injury. To obtain optimal incentives for injury prevention, a party that has violated a legal standard must pay full losses to the victim, including both pecuniary and non-pecuniary losses.

The award of both pecuniary and non-pecuniary losses, however, is inappropriate for providing optimal insurance for unpreventable losses. The effort to extend insurance coverage through modern tort law represents a confusion of incentive objectives with insurance objectives. ${ }^{138}$ Third-party insurance payments administered through the tort system differ from firstparty insurance payments in two ways. First, as described in Section III, no first-party insurance market provides coverage of non-pecuniary losses. ${ }^{139}$ Non-pecuniary losses do not affect the marginal value of wealth across states of the world. In addition, moral hazard and adverse selection problems make coverage of these losses exceedingly costly. Losses representing pain and suffering or other emotional effects of an injury, therefore, are never insured in first-party markets because it is not worthwhile for consumers to pay the premiums necessary to support coverage of them.

Secondly, deductibles and co-insurance are features of every first-party insurance contract. Third-party insurance through the tort system, in contrast, never incorporates deductibles or co-insurance to control victim moral hazard. Yet victim moral hazard is as serious a problem in a thirdparty context as in a first-party context. Preferences for extra visits to a doctor, prolonged hospitalization, or more advanced forms of medical treatment do not diminish because the source of the injury is a third-party defendant.

These two differences mean that, for the same injury, first-party insurance coverage-which corresponds to what consumers are willing to purchase-is substantially different in magnitude than the third-party insurance coverage provided through tort law. First, awards for pain and suffering and other non-pecuniary losses are known to comprise a large

138. This point is emphasized in M. Trebilcock, supra note 72 , at 3 .

139. For earlier discussions of this point, see Danzon, Tort Reform and the Role of Government in Private Insurance Markets, 13 J. Lrcal. Srud. 517 (1984); Rea, Nonpecuniary Loss and Breach of Contract, 11 J. Lricial. Srun. 35 (1982). 
portion of tort damages: the most commonly mentioned figure is $25 \%$ to $50 \% .{ }^{140}$ More detailed empirical studies of trial awards-studies of awards in Cook County, Illinois-show that non-pecuniary losses comprise $47.2 \%$ of total tort damages. ${ }^{141}$ Thus, to approximate, out of the median products liability judgment of $\$ 187,000$ in Cook County $(1980-84),{ }^{142} \$ 88,264$ represents pain and suffering against which the typical consumer would not choose to insure.

The remaining portion of the average damage judgment represents compensation for pecuniary losses, chiefly lost income and medical expenses. Recoveries for these losses in an active first-party insurance market, however, are also likely to be significantly more modest than under third-party tort law insurance. For example, virtually all United States workers are covered by state workers' compensation plans that provide coverage for lost wages subject to a strict income ceiling. In Illinois, for example, the maximum weekly benefit is $\$ 376.33^{\mathbf{1 4 3}}$ (for fifty-two weeks, $\$ 19,569$ ), which corresponds to a $\$ 30,000$ annual income. Even for workers with incomes equal to or below $\$ 30,000$, the precise coinsurance level is difficult to determine since workers' compensation benefits (like the lost income component of tort judgments) are net of income taxes. Workers' compensation plans also provide for lump-sum payments for different forms of permanent disability. In sum, the best recent estimate is that net workers' compensation benefits provide .835 income replacement. ${ }^{144}$ Lost income, on average, constitutes slightly over half of pecuniary damages. ${ }^{145}$ The lost income component of the median Cook County product liability judgment, then, would be roughly $\$ 49,368$ of which the victim, under workers' compensation, would receive $\$ 41,222$ and suffer individually $\$ 8,146$.

Similarly, with respect to medical expenses, the typical Blue Cross-Blue Shield policies provide an average deductible of $\$ 1000$ (per member) and coverage of $80 \%$ of service costs. ${ }^{146}$ Similarly, the typical Blue Cross major

140. See M. Peiterson, Compensation of Injuries: Civil. Jury Verdicts in Cook County 21 n.6 (Rand Corp. Report No. R-3011-ICJ, 1984) (reporting views of lawyers and claims adjusters).

141. Derived from id. at 14 and M. Perrerson \& G. Prikst, supra note 68, at 23.

142. M. Pritr.rson, Givil. JuRies in THE 1980s: Trends in Jury Trials and Verdicts in Galifornia and Cook County, Il.linois 21 (Rand Corp. Report No. R-3466-ICS 1987). The mean verdict over the same period was $\$ 828,000$, for which the disparity between the first-party insurance amount and the tort judgment would be far greater.

143. Vicitor, Cohren \& Phil.ps, Workers' Comprnsation and Workpl.ace Safety 15 (Rand Report No. R-2918-ICJ, 1982).

144. Viscusi, Economic Implications of Liability for Job Accidents, at n.14 (1987) (unpublished manuscript on file with author).

145. Derived from M. Prirkson, supra note 140, at 14, 19. I am assuming here that the weekly maximum is ineffective and that there is no lump-sum award for permanent disability, assumptions which work in opposite directions.

146. Bi.ue Cross-Bl.uk Shinl. of Connecercutr, The Comprehensive Healthcare Plan; (1985) (deductibles of $\$ 400$ and $\$ 1500$ are also available); Bi.ur: Cross-Br.ue: Shin.d of Connectr- 


\section{The Current Insurance Crisis}

medical plan covers only $80 \%$ of charges. Thus, under a typical first-party medical plan the victim would be reimbursed $\$ 38,694$ of the approximate $\$ 49,368$ medical expense component of the median Cook County product liability judgment and would pay $\$ 10,674 .{ }^{147}$

Even this crude estimate of the value of deductibles and co-insurance, however, fails to measure the effect of these payments on the level and character of medical care chosen by insureds. All first-party medical plans incorporate detailed limitations on the nature of available care and on the extent of specific forms of care. Blue Gross-Blue Shield plans, for example, limit coverage to semi-private room accommodations, limit coverage of hospitalization or of skilled nursing facility care to 120 days, and exclude coverage altogether of services such as "custodial care designed to assist an individual in meeting activities of daily life."148 Of course all consumers would prefer more coverage to less, but these limitations-though they force consumers sometimes to make difficult decisions about medical treatment-represent the best accommodation with the insurance premiums consumers are willing to pay. Because of moral hazard, additional medical services would require increases in insurance premiums beyond their value to consumers.

In contrast, under third-party insurance provided through tort law, there is little reason for the beneficiary of the insurance-the tort plaintiff - to engage in difficult decisions about appropriate levels of medical treatment. Both because of the specific policy care limitations and because every first-party insurance claimant must pay a not-insubstantial portion of medical costs, he or she must consider very carefully which medical procedures will be most effective as well as whether, and the extent to which, extended care is needed. The tort plaintiff, on the other hand, loses nothing by requesting (or asserting as essential) all available advanced methods of medical treatment regardless of cost.

The shift from first-party to third-party insurance sources, thus, will prompt greater expenditures for advanced medical care, as well as more extended and elaborate hospitalization and subsequent care. For example, holding severity of injury constant, the frequency of claims for twentyfour hour nursing care is likely to be substantially higher under thirdparty tort law insurance than under first-party insurance. ${ }^{149}$

Though rough, these estimates show substantial differences between in-

curt, Srim-Privaite: P1.An Benrfits (1985).

147. This assumption is quite rough. Some Blue Cross-Blue Shield Plans have out-of-pocket dollar limitations, although these typically apply only to basic health coverage and non-major medical.

148. See supra note 146.

149. There is some confirmation from studies of damage awards that have found the largest increases in medical damage claims in recent years in cases that involve more severe injuries, cases in which this moral hazard component is greatest. M. Prrrerson, supra note 140, at 23-27 
surance coverage in first-party markets and third-party insurance coverage provided through tort law. For the injury represented in the median Cook County judgment, the victim would have received first-party compensation of $\$ 41,222$ for lost income and $\$ 38,694$ for medical expenses. This coverage, $\$ 79,916$, is the amount for which the victim ex ante was willing to pay. In contrast, third-party tort insurance provided $\$ 187,000$ coverage which is 2.34 times greater than the first-party amount.

Tort law claimants do encounter costs not faced by first-party insurance claimants, though estimating their magnitude is difficult. Tort law claimants must pay attorneys' fees. In addition, in the vast majority of cases, tort claimants settle prior to trial for amounts less than the highest possible judgment. Regardless of settlement, some tort judgments are reduced under comparative negligence standards. There are analogues to these costs, however, under first-party insurance coverage. If the first-party insurer contests the claim, the first-party claimant must pay attorneys' fees. Similarly, many first-party claims involve negotiation and settlement at some figure less than the full amount demanded by the claimant.

To my knowledge, there are no studies attempting to measure differences between first-party and tort law insurance claims in these areas. Even if tort law insurance claims were reduced by $30 \%$-which is probably a high estimate (the standard contingent fee for a case expected to be litigated is 33\%) - the tort judgment in the Cook County example would still be 1.64 times the comparable first-party insurance award. Estimated conservatively, then, tort law insurance coverage levels are in the range of $64 \%$ to $134 \%$ greater than first-party coverage levels.

Some might regard the additional level of insurance coverage provided by tort law to be beneficial to consumers because it affords them greater compensation for the injuries they suffer. But this view misunderstands the consumer interest in insurance. Of course, after an injury has been suffered, the victim would prefer a greater to a lesser award. But the ex ante interest of the victim is an award tied to the victim's pecuniary losses, not an award greater than these losses. Where the victim is the product or service purchaser, the victim must pay for the insurance in advance. To compel insurance greater than the amount demanded by the purchaser reduces, rather than increases, his or her welfare. To illustrate: if my $\$ 100,000$ home burns down, I of course would be happier if my insurer gave me $\$ 234,000$ rather than the $\$ 100,000$ of coverage I purchased. But, I would object strongly if I were compelled in advance of the fire to purchase $\$ 234,000$ coverage since I could replace the home in its entirety for an amount in the range of $\$ 100,000$. A similar concern for optimal insurance extends to contexts involving pure third-party injuries-for example, when bystanders are harmed by the product or service use of 
others. In modern society, all of us are at once product and service purchasers and bystanders of products and services used by others. Again, in terms solely of insurance, each of us ex ante prefers that the optimal level of insurance be provided by tort law, the level that optimizes insurance coverage subject to insurance costs. ${ }^{150}$

The provision of insurance coverage through tort law in amounts greater than consumers would willingly purchase has additional effects that implicate the recent crisis. An increase of $64 \%$ to $134 \%$ in the level of insurance coverage under tort law will not operate as a scalar, but will increase consumer risk pool variance and will lead to the unraveling of consumer risk pools.

The increase in the level of insurance coverage from the shift to the third-party tort mechanism is not likely to be uniform over all cases. The empirical observation that pain and suffering awards constitute $47 \%$ of total damages is an average figure. Pain and suffering and other nonpecuniary amounts comprise a much higher proportion of large damage judgments. For this reason, risk pool variance is likely to be greater under third-party tort insurance than under first-party insurance. ${ }^{161}$

More importantly, segregating risks into narrow risk pools is substantially more difficult in third-party than in first-party insurance contexts. First-party insurers, by using insurance applications, can distinguish insureds by age, income, occupation, the level of coverage desired, and other personal characteristics related to levels of risk brought to the insurance pool. Moreover, the administration of first-party insurance allows the insurer to distinguish insureds by past loss experience. The collection of these data allows a first-party insurer to define risk pools of very narrow scope, increasing the likelihood that low-risk individuals will find insurance attractive. Narrow risk differentiation maximizes the availability of insurance.

Very little information about individual risks, however, is available to third-party insurers. A product manufacturer, for example, may design and market a product with reference to characteristics of discrete sets of average consumers. But the manufacturer must sell the product on equivalent terms to all who wish to buy it, and cannot distinguish among

150. Cf. J. Rawis, A Throky of Justick: (1970).

151. In addition, even if this percentage increase were uniform for all claims, a selective effect would lead to a resorting of those claims filed, pressed and successfully recovered, which will increase risk pool variance. Litigation costs vary by the size and merits of the claim. There are large fixed costs in the preparation of any tort claim. As a consequence, large claims tend to be overrepresented in any trial or settlement sample. See Priest \& Klein, The Selection of Disputes for Litigation, $13 \mathrm{~J}$. LEGAL Srun. 1 (1984). Virtually all discussions of recent increases in the size and frequency of large judgments in litigated cases fail to take this selection effect into account. See, e.g., DOJ REPORT, supra note 24 , at $36-40$. Stated otherwise, low value tort claims-those that reduce the average claim in a risk pool (the low-risk)-are more likely to be culled from the pool, increasing pool variance. 
consumers with respect to the insurance policy provided in the product price.

Some products, of course, will attract relatively homogeneous sets of consumers. A very wide range of products, however, are accessible to and are purchased by consumers of different income levels. Studies of consumers of individual products show that, for virtually all products, the income levels and personal characteristics of consumers of the product differ widely. ${ }^{162}$

The difficulty of segregating risk pools in third-party contexts means that third-party tort insurance pools are likely to be substantially broader than first-party pools even without the effects, described above, of levels of coverage. Compare, for example, the risks of non-preventable injuries from auto use. ${ }^{153}$ The first-party insurer can create separate driver pools for teenagers and other age groups; it can segregate insureds by levels of driving, total mileage, distance from home to office, and car type; and it can rate the policies by accident experience and by moving violations within previous time periods. It can allow the insured to choose whether to purchase medical expense and disability coverage in the auto policy or to rely on separate medical and disability policy coverage set according to the deductible the insured prefers and according to the insured's income level. Each of these techniques helps keep premiums low for the low-risk drivers of the consuming population-those who drive little, are very skilled or careful, or generate small claims because of low expected income losses.

In contrast, the auto manufacturer-that must buy third-party liability insurance for all those injured in its cars and pass on the premiums in vehicle prices-can implement none of these distinctions. Some auto models may be more or less attractive to commuters, to teenagers, or to the very wealthy, but, except for these crude distinctions, the auto manufacturer must provide insurance to all who buy the model, high-risk and low-risk alike. Consequently, the variance in the insurance pool is vastly greater in the third-party context, and the premium is commensurately higher-even if the same level of coverage is offered. Of course, given the greater amount of coverage provided under a third-party policy, the variance and the premium are higher yet.

One of the most seriously deleterious effects of lumping consumers into undifferentiated third-party risk pools is glaringly inconsistent with the judicial objective of aiding the poor. That is the regressive redistributional effect of third-party insurance. The largest items of damages in most

152. E.g., Frderai. Trade Comm'n, Warrantifs, Rul.es, Consumer Follow-up Study (Draft Final Report 1983).

153. See also Epstein, supra note 102, at 668. 
third-party personal injury contexts, especially those involving permanent disability, are lost income and pain and suffering, which are highly correlated with individuals' expected future income streams. As a consequence, these damage elements constitute the largest component of the third-party insurance premium tied to the sale of any product or service.

The third-party premium is set with reference to average expected loss. Thus, the high correlation of total awards with income means that premiums reflect the average income of the population of consumers. The implication of charging each consumer a premium related to average income is that consumers with high incomes are charged a premium lower than their expected loss, and consumers with low incomes are charged a premium higher than their expected loss. Third-party insurance thus requires low-income consumers to subsidize high-income consumers.

Moreover, third-party insurance requires low-income individuals to subsidize both pecuniary and non-pecuniary losses of high-income individuals. Compare the insurance premium that a low-income consumer would pay in a first-party auto, product, or disability policy to the premium tied to the product or service in a third-party provider policy that includes coverage to the high-income consumer. The auto or product manufacturer cannot charge the low-income consumer a lower price based on the lower dollar risk the consumer brings to the risk pool. The first-party casualty or disability carrier can do so, and thus can increase the availability of insurance.

As a consequence, the disadvantages of third-party insurance coverage are substantial. Courts justified third-party insurance coverage based on how easy it seemed to be for manufacturers or service providers to aggregate risks by adding an insurance premium to the price of the product or service. ${ }^{164}$ Whatever comparative advantage providers enjoy in risk aggregation, however, is overwhelmed by the disadvantages of excessive coverage, the inability to segregate risks in third-party contexts, and regressive distributive effects.

How do the differences between first-party and third-party tort insurance mechanisms affect the behavior of consumers? The shift towards greater corporate-provided tort law insurance will lead low-risk consumers to reduce consumption of products whose prices incorporate high tort insurance premiums. For low-risk consumers, especially low-income consumers, the tort law insurance premium tied to the product or service price may be much greater than the benefit the insurance provides. As a

154. Manufacturers, of course, cannot possibly have a comparative advantage to insurers in terms of creating risk pools. The purported aggregation advantage of manufacturers must be with respect to the transaction costs of entering into an insurance contract. 
consequence, though the effect may be subtle, these consumers will drop out of the market. ${ }^{155}$

The delivery of insurance through tort law exacerbates this effect for a reason unrelated to the maintenance of insurance risk pools. The administrative costs of insurance delivered through tort law are vastly greater than the administrative costs of any first-party insurance regime. Blue Cross-Blue Shield first-party health insurance administrative costs are $10 \%$ of benefits; SSI disability insurance administrative costs are $8 \%$ of benefits; Workers' Compensation disability insurance administrative costs are (a much-criticized) $21 \%$ of benefits. ${ }^{156}$ In contrast, tort law administrative costs are estimated to be $53 \%$ of net plaintiff benefits. ${ }^{187}$

The relatively greater administrative costs of the tort system must be averaged over the sale of all products and services. ${ }^{188}$ As a consequence, they operate in the manner of a sales tax on product and service delivery. Like a sales tax, their incidence has a regressive redistributional effect: They represent a greater proportion of the resources of the poor than of the moderate- or high-income population. Thus, low-income persons are harmed doubly by the delivery of compensation insurance through tort law: They pay premiums greater than their expected return, and they pay a fixed-rate levy that affects them more severely than those consumers possessing greater resources.

\section{B. Why Provider Risk Pools Have Unraveled}

The shift from first-party to third-party insurance coverage also influences market insurance consumption by providers of products and services. Provider risk pools unravel because providers are more likely to self-insure under a third-party than under a first-party tort insurance regime. This result stems from the process and determinants of corporate self-insurance.

It is not obvious why corporations buy market insurance in any form. Corporations are far more able than individuals to diversify their assets to reduce the risk of unfavorable outcomes. Moreover, corporate sharehold-

155. Some commentators have alleged that, in particular contexts, particularly automobile casualty insurance, the limits on mandatory insurance may lead some low-income individuals into differentially engaging in high-risk activities because of the relatively greater likelihood that the damage judgment will exceed the person's assets. The best example is a teenage driver. See Keeton \& Kwerel, Externalities in Automobile Insurance and the Underinsured Driver Problem, 27 J.L. \& EcoN, 149 (1984). The magnitude of this effect, as well as its applicability to any contexts involving product or service use, is unclear.

156. See G. Prirsir, supra note 136, at 21-22.

157. J. Kahal.ik \& N. Pace, Gosts and Compensaition Paid in Tori Lritiation 71 (Rand Corp. Rep. No. R-3391-ICJ 1986).

158. More precisely, $29 \%$ of tort judgment amounts represent defendants' costs, averaged to all users and consumers; $24 \%$ represent plaintiffs' costs, charged differentially to individual claimants. $I d$. 
ers can diversify cheaply. ${ }^{180}$ What are the justifications for further diversification through market insurance?

In fact, a very large majority of corporations purchase commercial casualty insurance. A Fortune survey in 1973 showed that $86 \%$ of its top 500 industrial corporations purchased insurance against an aggregate $75 \%$ of their perceived loss exposure. ${ }^{160}$ Some of this insurance undoubtedly represents the purchase of risk monitoring or claims administration services from commercial casualty insurers. ${ }^{161}$ There are also tax advantages to market insurance. ${ }^{\mathbf{1 6 2}}$ Insurance purchased for these reasons, however, is not likely to be affected in the current insurance crisis. ${ }^{\mathbf{1 6 3}}$

There are several reasons, however, for corporations to purchase commercial casualty insurance to protect against potential legal liability. ${ }^{\mathbf{1 0 4}}$ Market insurance reduces the risk of variance in the asset level of the firm. Insurance, thus, protects the position of corporate bondholders, and may be demanded in order to generate bond investment. Moreover, a corporation incurs very real costs when it must adjust its activities to dispose of assets in order to fulfill liability obligations. An extreme example is the risk of bankruptcy and the consequent change in the value of corporate assets upon reorganization. Corporations will purchase market insurance when market insurance premiums are less than the expected value of these real costs. In contrast, when market insurance premiums exceed these costs, firms will self-insure by maintaining reserves or by anticipating partial (or in the extreme case, total) liquidation of assets to meet liability claims.

How is the shift to third-party tort insurance likely to affect the corporate demand for commercial casualty insurance? As described earlier, the increase in corporate tort liability has increased the variance in risk pools comprising consumers of corporate products and services. This increased variance, of course, increases the individual riskiness of each corporate provider, requiring an increase in the corporate casualty premium. The value of a corporation's assets, however, is never infinite. At the limit, corporations will never purchase market insurance if the insurance premium is greater than the costs of liquidation, discounted by the likelihood

159. These considerations do not apply to close corporations or corporations whose basic assets are individual human capital, such as doctors or other professionals.

160. Main, Corporate Insurance Purchases and Taxes, 50 J. Risk \& INs. 197 (1983) (citing

For'tunE, HoW Major CORPORATIONS VIEW PROPER'TY/LIABILITY INSURANCE (1973)).

161. Mayers \& Smith, supra note 127 , at 285-86.

162. Id. at 289-93. See generally Main, supra note 160 .

163. There may be a reason for a corporation to increase market insurance, however, if it will cover punitive damages, since insurance premiums are tax deductible, but punitive levies are not.

164. See Mayers \& Smith, supra note 127, at 283-84; see also Mayers \& Smith, Contractual Provisions, Organizational Structures and Conflict Control in Insurance Markets, 54 J. Bus. 407 (1981). 
of its occurrence. As corporate liability exposure increases, the gap between market insurance premiums and discounted liquidation costs diminishes.

The increase in corporate riskiness affects the commercial casualty insurance market in an additional way. The effect of the expansion of corporate liability varies for different companies, depending upon the risk characteristics both of a company's product or service and of its consumers. The shift to greater third-party tort insurance coverage increases these differences among firms.

If commercial casualty insurers are able to predict how firms differ in riskiness, then they can tailor an insurance premium appropriately for the risk that underwriting the particular corporation adds to the insurer's portfolio. The sale and purchase of commercial casualty insurance, however, requires a convergence of risk estimates by the insurer and the corporation. When the insurer believes that the risk level of a firm is greater than the firm believes it to be, the firm is likely to find self-insurance more attractive than market insurance. Obviously, when the insurer believes the risk level of a firm is lower than the firm believes it to be, the firm will prefer market insurance. If firms have better knowledge of their underlying level of riskiness than insurers, these differences in expectations will lead relatively low-risk firms to drop out of the insurance pool and relatively high-risk firms to stay in the insurance pool. This is adverse selection in the commercial casualty market.

The shift to corporate tort liability increases the extent of adverse selection. Individual firm riskiness and the variance of individual riskiness among firms both increase as the scope of liability expands. These increases in the range of potential liability outcomes across firms increase the likelihood of differences in insurer and corporate estimates of underlying corporate riskiness. As a consequence, adverse selection is likely to increase. Low-risk firms are increasingly likely to withdraw from the commercial casualty market, leading to an increase in premiums and an increase in the likelihood that the commercial casualty pool will unravel.

The increase in corporate liability exposure on the commercial casualty market will also affect insurance supply. As described earlier, the insurance function is achieved by the pooling of independent risks. Whether in the context of class underwriting or special risk underwriting, the efficiencies of insurance are obtained by the aggregation of independent risks in ways that reduce the underlying magnitude of each risk. It is crucial for this function, however, that the risks be independent. If the risks are correlated, then aggregating them may increase, rather than reduce, total riskiness.

All corporations offering products and services that might lead to per- 


\section{The Current Insurance Crisis}

sonal injury are subject to tort liability. The increase in corporate tort liability exposure, therefore, increases the correlation (the covariance) of these corporate risks. Increasing tort liability reduces the independence of risks within commercial casualty lines and imperils the insurance function. The reduction in independence of risks is the direct consequence of the shift to third-party tort insurance. Complaints, heard commonly, about the increased uncertainty of modern tort law and the difficulties this uncertainty places upon insurers can be best understood in these terms. ${ }^{165}$

The business of insurance is to deal with uncertainty. If the expansion of modern tort law had increased uncertainty in an unbiased fashion, it might have expanded, rather than contracted, commercial insurance markets. The increase in uncertainty, however, has not been unbiased: Uncertainty has increased only over the extent of worst-case tort outcomes, which is to say, the potential downside risks of corporate liability are far greater than they were two decades ago. And these downside risks are greater for most classes of corporate product and service providers. Thus, it is not uncertainty per se, but the increased correlation of corporate liability risks that has disrupted commercial casualty lines.

Most important in my analysis, however, is the effect of the increase in the correlation of corporate liability risks on adverse selection. As explained earlier, ${ }^{168}$ as risks become more correlated, premiums must increase, because the insurer's costs of diversification increase. The dramatic hikes in commercial casualty premiums, of course, reflect this effect, and it has been noted by other commentators. ${ }^{\mathbf{1 6 7}}$ Yet most commentators have ignored how the increasing correlation of risks exacerbates adverse selection. Increases in risk correlation alone do not explain why insurers have reduced levels of insurance coverage including the refusal to offer coverage at any premium in some commercial casualty lines. Similarly, increases in insurance premiums cannot fully explain why providers have removed products and services from the market. As we shall see in the next Section, adverse selection in both consumer and provider insurance pools does explain these and other phenomena of the insurance crisis.

\section{The Insurance Crisis Observed}

This Section demonstrates how the shift to third-party tort insurance coverage and the consequent increase in risk pool variance has weakened existing insurance markets and led to the unraveling of existing insurance risk pools. The Section examines first how consumer pools and second

165. See, e.g., R. WINTr.R, supra note 58; DOJ REPOR'I, supra note 24.

166. See supra text accompanying notes 111-13.

167. See R. Wintrik, supra note 58 . 
how provider pools have been affected by the expansion of corporate tort liability and the shift from first- to third-party insurance sources. It shows why providers have changed the nature of their product and service mix, including ceasing production altogether; why insurers have changed the terms of insurance policies to reduce coverage levels; why insurers have refused coverage on any terms in some commercial lines; and why still other providers have been forced to form industry-wide mutuals.

\section{A. The Effect of Increased Variance on Consumer Risk Pools}

The previous Section showed that the shift to third-party insurance sources increases the variance of consumer risk pools. An increase in risk pool variance obviously leads to an increase in real insurance costs. A firm subject to competition must add these costs to the product or service price.

Adverse selection in consumer risk pools occurs when some group of consumers chooses not to pay increased prices that include the higher level of third-party insurance. These consumers decline to purchase the product or service and, thus, drop out of the existing risk pool. The consumers most likely to drop out are the low-risk within the pool. In general, within any pool there will be two low-risk sets: those systematically less likely to suffer injuries at all and those whose injuries systematically generate lower real costs.

Consumers who systematically face a lower injury probability are likely to find the insurance provided with the product or service not worth its added premium. Many commentators have tended to view product- or service-related injuries as occurring randomly, ${ }^{188}$ generating an equal injury probability to each consumer. Many product- and service-related injuries, however, are systematically associated with particular product uses. Most modern products can be employed in a wide range of diverse activities. Those consumers who use products in typically less, rather than more, risky ways are likely to drop out of the consumer pool if tort law requires the manufacturer to insure all consumer uses. These consumers will shift to alternative products or services that cannot be used in equally risky ways-products which, as a consequence, will be cheaper because of the lower attendant insurance premiums.

A familiar modern example is consumers of four-wheel drive vehicles. In recent years, the liability of manufacturers of such vehicles has been expanded under design defect and warning law and, more generally, as courts have limited the defenses of contributory negligence, misuse, and

168. See Brown, Product Liability: The Case of an Asset with Random Life, 64 AM. EcoN. Rrv. 149 (1974); Spence, Consumer Misperceptions, Product Failure and Producer Liability, 44 REv. Econ. Siud. 561 (1977). 
assumption of risk. ${ }^{169}$ Manufacturers have been held liable, for example, for injuries suffered when these vehicles have rolled or flipped in contexts of extreme mountain driving on grounds that the manufacturer could either design the product to better protect the consumer or insure the consumer for the loss. ${ }^{170}$

Manufacturers must respond to this increased liability either by changing product design to protect drivers in extreme conditions or by increasing insurance coverage for the consumer set as a whole. Whether the manufacturer changes the design or merely increases insurance coverage, product costs will increase and the product price will increase. The price increase, of course, may seem desirable for consumers who drive in extreme backroad conditions. But consumers who purchase four-wheel drive vehicles for other purposes-say, easier driving on snowy or muddy roads-may not find the increased price worthwhile. These consumers could be lured away if they were offered a four-wheel drive vehicle suitable for snow and mud, but not for extreme grades which, if only because of the lower attendant insurance premium, could be offered at a lower price. It is not surprising that many manufacturers have begun offering van and station wagon models with a four-wheel drive option.

This process is adverse selection in the product market. Prior to the expansion of manufacturer liability, the vehicle was sold without insurance for losses resulting from flips or rolls. Consumers who enjoyed backcountry travel insured themselves for such losses in first-party insurance markets. The expansion of manufacturer liability shifted the insurance source to the third-party mechanism. Because the manufacturer was prohibited by product liability law from making this additional insurance optional, ${ }^{171}$ low-risk consumers within the pool-those not intending to expose themselves to backcountry risks-dropped out of the pool, either by shifting to domestic four-wheels, or by declining to buy the product at all. When low-risk consumers drop out, the insurance premium added to the price of backcountry four-wheels must be increased by an ever greater amount.

The second set of low-risk consumers affected by the expansion of provider liability are the low-income or poor, who bring low risks to a liability insurance pool because of the lower damages they will receive because of their lower income and poorer future employment prospects. As the insurance premiums tied to products and services increase, these consumers also drop out because the price they must pay is increasingly greater

169. See, e.g., Jeep Corp. v. Murray, 101 Nev. 640, 708 P.2d 297 (1985).

170. See, e.g., Leichtamer v. American Motors Co., 67 Ohio St. 2d 456, 424 N.E.2d 568 (1984).

171. See Henningsen v. Bloomfield Motors, 32 N.J. 358, 161 A.2d 69 (1960) (refusal to enforce disclaimers of liability for personal injury in automobile warranties). 
than the value received. Such consumers will shift to substitute products for which the consumer set is more homogeneous in terms of income or for which the underlying risk level is lower. Of course, an income effect is also likely to be important here: Such consumers will discontinue buying products with large insurance premiums because, given their available resources, they cannot continue to afford them. Again, as this set of low-risk consumers drops out, the attendant insurance premiums must be commensurately increased.

Adverse selection in consumer risk pools explains why the increase in insurance premiums has been extreme for products and services in recent years. It also provides the only explanation of why increases in corporate tort liability compel providers to withdraw products and services from markets altogether. Again, if there were no adverse selection, increases in insurance premiums or self-insurance costs could largely be passed on to consumers. Sales may decline, as must be expected from any price increase, but there would be no reason to withdraw products from the market. There is a different effect, however, where a price increase derives from increasing risk pool variance. Increasing variance generates adverse selection by low-risk consumers who successively drop out of the pool. The pool, as a consequence, unravels. At some point, demand for the product sold with the necessary insurance premium simply disappears. There remains no set of identifiable consumers to whom the product or service is worth its price.

There is substantial evidence of these phenomena in the recent insurance crisis. Increases in insurance premiurns, sometimes extraordinary increases, have been reported. ${ }^{172}$ In many cases, providers have been able to pass on these premium increases to consumers. Some ski areas have increased lift tickets by $\$ 2$ to $\$ 3$ per day. ${ }^{173}$ Insurance costs now add $\$ 80,000$ to each Beech aircraft ${ }^{174}$ and $\$ 75,000$ to each Piper aircraft. ${ }^{178}$

Many firms, however, have had difficulty passing on increases in premiums or self-insurance costs. Some firms have made greater investments in product or model differentiation in order to attempt to segregate lowrisk from high-risk consumers, such as in the differentiation of domestic from backcountry four-wheel drive vehicles, described above. It is difficult for others than industry experts to distinguish insurance from consumer preference grounds for product differentiation, but there is some strong evidence of this trend at least with respect to more extreme risks. Some

172. See infra text accompanying notes 216-21.

173. Sorry, Your Policy Is Cancelled, supra note 2, at 19. For other discussions of the effects of insurance premium increases on the ski industry, see N.Y. Times, Feb. 15, 1986, at 1, col. 1; Wall St., J., Jan. 21, 1986, at 31, col. 1.

174. Sorry, Your Policy Is Cancelled, supra note 2, at 18.

175. Foriune, Mar. 3, 1986, at 20, 23. 
bus companies, for example, are reported to have terminated charter transit to ski areas because of the relatively higher risks of icy roads. ${ }^{176}$ In addition, as noted earlier, one New York vineyard has terminated or severely curtailed wine-tasting from fear of host liability for alcohol-related injuries. ${ }^{177}$ Public parks that have removed playground equipment or school districts that have removed diving boards from swimming pools are other examples of the effect. ${ }^{178}$ By excluding such services, these entities reduce the variance of risks related to the services they continue to provide.

The large number of products and services that have been totally withdrawn from markets demonstrate the severity of the effects of contemporary tort law's shift to the third-party insurance mechanism. Except for a few particularly notorious examples, product and service withdrawal tends to be effected silently, ignored as consumers shift to alternative sources that are higher priced or less convenient for their needs. It was recently reported, however, that vaccines and pharmaceuticals have been withdrawn, despite prior FDA approval. ${ }^{179}$ Cessna Aircraft terminated several small plane models because insurance costs (estimated at $\$ 75,000$ per plane) had pushed prices beyond the reach of its consumers. ${ }^{180}$ Similarly, the G.D. Searle Co. recently terminated sales of intrauterine devices in U.S. markets. Searle's annual sales volume for the devices was $\$ 11$ million, but it spent $\$ 375,000$ defending each product liability action brought by users of the IUDs. ${ }^{181}$ Litigation costs of this dimension are not likely to persist once the novel liability issues with respect to the product are resolved. But even a dramatic reduction in litigation costs per case may not make the intrauterine device price-competitive with other means of birth control.

Product and service withdrawal, however, has extended far beyond the limited examples reported in the press. Very recently, a Conference Board survey of the nation's 500 largest corporations showed that twenty-five percent had removed products or services from markets. ${ }^{182}$ Oddly, this datum was reported amidst the author's conclusion that the deleterious impact of the insurance crisis was exaggerated because firms were still profiting from sales of products they had not been forced to withdraw. The author confuses the existence of corporate profits with consumer welfare.

176. Wall St. J., Jan. 21, 1986, at 31, col. 5.

177. N.Y. Times, Mar. 26, 1986, at C12, col 4.

178. See supra text accompanying notes 16-17.

179. Sorry, Your Policy Is Cancelled, supra note 2, at 18.

180. Id. at 18-19; Wall St. J., Jan. 21, 1986, at 31, col. 1 .

181. Brody, When Products Turn into Liabilities, ForTune, Mar. 3, 1986, at 20; N.Y. Times,

Feb. 1, 1986, at 1, col. 5; Wall St. J., Feb. 3, 1986, at 5, col. 1.

182. Conf. Bd., supra note 14. 
Consumers do not benefit from having fewer products and service choices (any more, from a broader view, than do corporations), even if quarterly corporate earnings exceed zero. Of course, it is even more difficult to estimate the extent to which new products and services were never introduced because of the expansion of liability.

Other markets have suffered similar insurance-related dislocations. Many commentators, for example, have been puzzled by the large reduction in the availability of some medical and health care services, obstetrics in particular. A 1983 survey reported that $34.6 \%$ of doctors nationwide refused to accept certain types of cases because of increased liability. ${ }^{\mathbf{1 8 3}}$ Time reports that nearly one-eighth of American obstetricians have abandoned the specialty. ${ }^{184}$ This is puzzling because, given the absence of available substitutes, the demand for obstetrical services is likely to remain relatively firm over time. It ought to be easy, therefore, for obstetricians to pass along malpractice premium increases to their patients. ${ }^{185}$

Blue Cross-Blue Shield and other medical insurers, however, in efforts to control costs to make health insurance more attractive to low-risk consumers, have imposed strict price restrictions on certain medical procedures, including child delivery. Recently, a group of doctors in Springfield, Massachusetts refused to perform deliveries for Blue Shield insureds because of low reimbursement rates. According to the report, Blue Shield will not pay more than $\$ 670$ for a normal delivery in the area; Medicare pays $\$ 507$. The doctors claimed that the average fee to private patients, a fee set partly with respect to rising malpractice premiums, was $\$ 1200 .{ }^{188}$ The malpractice premium is extremely high for obstetricians because of the extraordinary variance that results from the attribution of subsequent physical or emotional ailments to problems at delivery. If the payments for obstetrical services by the first-party insurers discussed here are representative nationally, however, it is not surprising that obstetricians, despite investments in developing their special skills, have shifted to the practice of other medical specialties for which the returns on their investments will be greater.

The conflict between containing costs to reduce health insurance premiums and sustaining an optimal level of services pervades the health care industry. ${ }^{187}$ The conflict is especially severe when the malpractice-induced

183. Zuckerman, supra note 31, at 132; see also Danzon, Medical Malpractice: An Overview of the Issues 12 (1987) (unpublished manuscript on file with author) (reporting that $23 \%$ of OBG specialists have stopped performing certain high-risk procedures).

184. Sorry, Your Policy Is Cancelled, supra note 2, at 18.

185. The 1983 survey showed that $31.4 \%$ of doctors nationwide had increased fees in response to increases in malpractice insurance premiums. Zuckerman, supra note 31, at 132.

186. New Haven J. Courier, Jan. 29, 1986, at 28, col 3.

187. See Wall St. J., Jan. 21, 1986, at 31, col. 1. 
injuries can become manifest after some long delay (the liability tail problem) and where the medical procedure is standardized (like a normal delivery) so a fixed reimbursement fee can be easily administered. Thus, physicians providing standardized medical procedures with long tail liability implications are more likely to shift to other medical specialties until the large health insurers change their reimbursement policies or courts learn that imposing liability on insurance grounds for losses of this nature is counterproductive. ${ }^{\mathbf{1 8 8}}$

It is important to distinguish, at least analytically, between products and services withdrawn for insurance reasons and for deterrence or incentive reasons. Some products or services may simply generate so many injuries that continued production is infeasible. A legal standard that attached liability where the marginal expected injury costs exceeded the marginal costs of preventing the injury (here, the bare cost of production) would be sufficient to drive such products and services from the market and, thus, increase social welfare.

In contrast, the product and service withdrawal that harms consumers and reduces social welfare derives from the expansion of liability on insurance grounds, where the shift from first- to third-party insurance increases the variance or reduces the independence of risks enough to cause the risk pool to unravel. For example, many vaccines are known to be beneficial to large majorities who receive them, but to cause adverse reactions in some small number of individuals. If the adverse reactions truly cannot be prevented, and if the benefits of the vaccine exceed production and injury costs, then liability for adverse reactions is solely an insurance question. The important issue, however, is whether it is cheaper to insure for these reactions through either a first-party or third-party mechanism. As shown above, first-party mechanisms are typically superior in defining the level of insurance coverage and in segregating consumers according to levels of coverage appropriate to their income. The shift from first- to third-party insurance recovery can lead to the unraveling of the pool and the withdrawal of the vaccine from the market.

The point is that, for some products and services, insurance pools could be maintained on a first-party basis that could not be maintained on a third-party basis because of adverse selection. It is for these products and services that the expansion of tort liability on insurance grounds-beyond that level set to create optimal safety incentives-is most harmful. In con-

188. In contrast, other regulated enterprises can pass along increased insurance costs with commission approval. For example, the Century Cartage Company, a small trucking firm, was allowed by the Georgia Public Service Commission-which presumably restricts entry into the industry-to pass along to consumers part of its increases in insurance premiums. Sorry, Your Policy ls Cancelled, supra note 2 , at 16. 
trast, products too risky or injurious to produce at all could not support either first- or third-party insurance markets. Asbestos may be such a product. Obviously, asbestos production in the United States has stopped entirely because of the substantial third-party manufacturer liability. Quite possibly, asbestos-related injuries could not be insured in first-party markets either. Diseases without probabilistic features-inevitable diseases-are uninsurable because risks are not uncorrelated. It is difficult to believe that park slides, diving boards, vaccines, and other products and services recently withdrawn share this feature.

\section{B. The Effect of Increased Variance on Provider Risk Pools}

The increase in the variance of consumer risk pools from the shift toward greater third-party insurance delivery, of course, increases the risk of each individual provider. Section IV showed how this effect enhanced adverse selection and how the concomitant increase in correlation of corporate risks aggravated the problem. Adverse selection in provider risk pools consists of the relatively low-risk providers dropping out of the pool to self-insure. ${ }^{18 \theta}$

What are the forms of self-insurance that low-risk providers have selected? There has been a massive shift in recent years toward selfinsurance through the formation of captive insurance subsidiaries offshore in the Caribbean. ${ }^{190}$ Apparently, the subsidiary form assures deductibility of reserves; off-shore jurisdictions are attractive because of liberalized reserve requirements. ${ }^{191}$ A slightly different form of selfinsurance in response to the crisis has been the formation of industry-wide mutuals, such as by doctors and surgeons, who believe they are better able to judge their exposure (or control their exposure) than insurers believe. ${ }^{182}$ Although the extent to which low-risk providers have recently shifted toward self-insurance is poorly documented, it is known that selfinsurance rather than market-insurance constitutes a very substantial share of many specific commercial insurance lines. ${ }^{103}$

189. Note that when the relatively high-risk providers discontinue the provision of products and services, the effect is the reverse.

190. N.Y. Times, Mar. 7, 1986, at D1, col. 3, D4, col. 1.

191. See Mayers \& Smith, supra note 127, at 287 (importance of adopting some corporate form beyond simple reserve set-asides to allow deductibility).

192. Patricia Danzon reports that $40 \%$ percent of the physicians and hospitals are now insured through small mutual insurance groups. P. DANZoN, supra note 31 , at 93 . These groups write $50 \%$ of total malpractice coverage. Danzon, supra note 183, at 1.

193. Tillinghast estimated in 1986 that self-insurance composed $47 \%$ of the property/casualty market, although the broker Fred S. James \& Co. estimated the amount at $25 \%$. Taravella, Alternative Risk Financing Growing in Popularity, Bus. INs., Jan. 26, 1987, at 3, 14. Separately, Mitchell J. Cole of Tillinghast estimates self-insurance contributions will equal $50 \%$ of commercial insurance by 1989. Aschkenasy, Self-Insurance Gaining on Commercial Carriers, NAT'L UNDERwrITER, Mar. 9, 1987, at 1, col. 4; see also supra note 34 . 
The shift of the low-risk toward self-insurance, of course, places substantial pressure on the market insurance function: at the extreme, the pool unravels and the affected commercial risks become uninsurable. Insurers have strong interests in preventing this course of development. Since the early 1980's, insurers have been progressively changing the terms of the basic commercial insurance policy in order to make market insurance more attractive to low-risk providers in order to keep them in market insurance pools. These changes in basic levels of coverage have been accelerated since 1986.

Insurers have changed coverage terms in commercial policies in three separate ways: increasing deductible and coinsurance levels, lowering aggregate policy limits, and expanding coverage exclusions. As we shall see, each of these changes reflects an effort to make the commercial policy more attractive to the relatively low-risk within provider pools. In effect, these changes reduce the level of commercial coverage offered to providers. Yet, despite the effective reduction-in many cases, the sharp reduction-in the level of commercial insurance coverage, insurers have simultaneously been forced to raise commercial premiums substantially and in some markets ultimately to refuse to offer coverage altogether. Most commentators have focused on the increase in premiums and the refusal to offer coverage as characteristic of the crisis. ${ }^{194}$ The premium increases and coverage withdrawals, however, are only more prominent than the other fundamental changes in commercial casualty policies; each is a symptom of the progressive unraveling of provider pools. Each reflects an effort by insurers to fight off modern tort law's stimulus of adverse selection in order to try to maintain a commercial insurance market.

Insurers have increased policy deductibles in a wide range of commercial markets. The insurance deductible for the city of Baton Rouge, Louisiana, for example, increased from $\$ 100,000$ in 1984 to $\$ 500,000$ in 1985. ${ }^{195}$ The Kennestone Hospital in Marietta, Georgia faced an increase in deductible from $\$ 1$ million to $\$ 2$ million. ${ }^{186}$ Deductibles, as described earlier, provide financial incentives to insureds to reduce the risk of loss. As changes in liability rules and the shift to third-party coverage increase risk levels, the marginal benefit from risk reduction also increases. Thus, it is not surprising that insurers have increased incentives to insureds to reduce risks.

Increasing deductible and coinsurance levels, however, serves an insurance purpose beyond heightened incentives. Deductibles and coinsurance

194. See, e.g., DOJ REPORT, supra note 24.

195. Bus. INS., July 8,1985 , at 1 . In addition, the carrier increased the premium from $\$ 116,000$ to $\$ 1.2$ million for the same amount of coverage.

196. Sorry, Your Policy Is Cancelled, supra note 2, at 19. 
narrow the level of risks brought to an insurance pool by discriminating against high-risk in favor of low-risk members of a pool. The identical deductible will be less costly to an insured who can control the probability of loss than to an insured who cannot. The incentives created by deductibles and coinsurance transform those members who are relatively more able to control losses into low-risk insureds, and those members relatively less able, into high-risk insureds. Put slightly differently, the recent increases in deductible and coinsurance levels increase the effective insurance costs paid by high-risk members (because they must pay the premium plus the increased deductible or retention) while constraining the effective insurance costs paid by the low-risk members. They are a way to keep low-risk members in an insurance pool. ${ }^{107}$

Increasing deductibles, in fact, is only one of the techniques insurers have adopted recently to differentiate low-risk members of pools with respect to probability of loss. The day-care industry, for example, has been heavily affected by the insurance crisis, apparently because of the many recent incidents of child sexual abuse, which are certain to generate civil claims. Virtually all insurers have excluded coverage for sexual abuse liability from their policies. ${ }^{198}$

Those insurers still writing day-care policies, however, have taken still other measures. Day-care insurers reportedly now make unannounced inspections to monitor day-care centers' operations. ${ }^{198}$ One large firm, Kinder-Care, has voluntarily installed large windows at its centers. ${ }^{200}$ Each of these more specific responses, like a deductible or coinsurance, reduces the risk level brought by the firm to the insurance pool. Those day-care centers better able to control their employees (and thus, from the standpoint of the insurer, at relatively low risk of liability for sexual

197. That low-risk insureds complain about increased deductibles does not mean that they do not benefit from the increase. Low-risk members complain when deductibles are increased, as any consumer complains of an increase in effective price. Low-risk insureds, however, would complain more (or leave the pool entirely) if the premium were raised by the amount necessary to sustain the previously lower deductible. For example, see the report of the decision of Hardee's Food Systems to select a deductible of $\$ 2$ million in conjunction with installing non-skid floors to minimize falls. According to risk manager Susan Werner, Hardee's "just buys insurance against catastrophe . . . We have a good loss prevention program." Bus. WEkK, supra note 34, at 122.

198. Sorry, Your Policy Is Cancelled, supra note 2, at 20. There is every reason that insurers should exclude coverage of such claims, and that their exclusions should be enforceable. Sexual abuse of children is not the form of probabilistic loss for which the insurance function is appropriate. It is unclear, however, whether courts will find these exclusions enforceable in the compelling context of a suit by an abused child against a day-care center with low assets and an insurer with substantial assets where the motivating judicial objective is to maximize insurance coverage. The complete withdrawal of insurers from day-care coverage is strong evidence that judicial efforts to force coverage of uninsurable risks of this nature are short-sighted, reducing the effective insurance levels.

199. Id. at 19.

200. Wall St. J., Jan. 21, 1986, at 31. 
abuse) can tolerate unannounced inspections and the installation of windows.

The second way insurers have responded to the threatened departure of low-risk carriers is the widespread lowering of aggregate insurance coverage. The city of Mississauga, Ontario, for example, recently suffered a doubling of its premium along with a reduction of its coverage from $\$ 15$ million to $\$ 7$ million. ${ }^{201}$ Insurers recently cut coverage for the city of Hartford, Connecticut from $\$ 31$ million to $\$ 4$ million. ${ }^{202}$ Other insurers have effectively lowered aggregate coverage by amending policies to charge legal expenses in defending claims against the policy limit. ${ }^{203}$ Of course, more specific exclusions of coverage, discussed next, serve to reduce aggregate coverage as well.

Like increased deductibles, the reduction of aggregate policy coverage also narrows risk pools by making insurance more attractive to parties that bring lower aggregate risks to the pool. Lowering aggregate insurance limits resembles an increase in deductibles, although it serves to enhance insurance availability for a different set of low-risk members than the set affected by changes in deductibles. The reduction of a basic policy limit from $\$ 15$ to $\$ 7$ million, as above, makes the municipal insurance policy more attractive to cities that face a greater likelihood of losses in the range of $\$ 7$ million, than to cities that face higher probable losses. ${ }^{204}$ The charge of legal expenses against the aggregate limit, similarly, will be differentially attractive to firms or cities according to the level of legal expenses they expect to face.

Reducing aggregate policy limits is another way of segregating those insureds with low levels of exposure from those with high levels of exposure. The low exposure insureds are charged a premium appropriate to their risk level. The high exposure insureds obtain equivalent coverage, and then must go elsewhere-into a different risk pool-to obtain either excess insurance or to self-insure for their remaining risks. The reduction in aggregate insurance limits, therefore, resembles the "no frills" products and services that are differentially attractive to some sets of consumers. The reduction in aggregate limits, by differentiating among insureds, extends insurance availability to the low-risk of the insured population, who

201. Toronto Star Field, Feb. 20, 1986, at $\Lambda 7$.

202. Sorry, Your Policy Is Cancelled, supra note 2, at 17.

203. See, e.g., the Directors' and Officers' policies offered by the American Home Assurance Company, 1986.

204. Even "low-risk" cities may have purchased $\$ 15$ million coverage in the past, because such potential losses were within the distribution of expected outcomes-although far from the mean. Cities for which $\$ 15$ million is close to the mean risk of loss are disadvantaged by the reduction in aggregate coverage. 
may not have purchased market insurance had they not been segregated from the higher risks.

Charging legal expenses against the policy limit may also serve an incentive purpose, like the deductible or coinsurance. An insured that knows that its liability coverage will be reduced by the amount of the insurer's legal expenses may itself strive to reduce those expenses, by handling more case management tasks within the firm (much like the expansion of corporate counsel) or, of course, by reducing the incidence of litigationgenerating activity. Again, firms or municipalities able to achieve such economies (and thus reduce the risks they bring to the pool) will find the new policy definition more attractive than firms unable to control legal expenses.

The third principal modification in insurance coverage adopted to restrain adverse selection is the introduction of multiple specific coverage exclusions in insurance policies. Municipal liability policies, for example, have been redrafted to routinely exclude coverage for pollution ${ }^{205}$ and for employment discrimination claims. ${ }^{206}$ Directors' and officers' policies have been modified, variously, to exclude coverage of claims related to mergers, acquisitions and tender offers, illegal payments, joint ventures, outside directorships, professional errors and omissions, ${ }^{207}$ and even for SEG liability ${ }^{208}$ Many directors' and officers' policies have been redrafted to exclude coverage of liability from pending or prior litigation, ${ }^{209}$ an exclusion resembling the widespread adoption of claims-made policies across commercial insurance contexts. ${ }^{210}$

Each of these coverage exclusions represents an effort to narrow risk pools and make them attractive to low-risk members. Those members of the pool who are less vulnerable to the respective sources of loss face fewer incentives to drop out of the pool, because the premiums they pay will diverge less drastically from the risk they bring to the pool. The exclusion from municipality policies of claims relating to pollution narrows the risk pool to those cities whose managers have never authorized, regulated, or otherwise monitored hazardous waste sites or waste disposal. Similarly, the exclusion of coverage for claims relating to mergers, acquisitions and tender offers in a directors' and officers' policy narrows the risk pool to treat equally directors whose firms are and are not active in the market for corporate control. These exclusions maximize the availability of insur-

205. Bus. INs., July 1, 1985, at 12 .

206. Bus. INS., July 8, 1985 , at 30 .

207. Professional errors and omissions coverage is often offered separately.

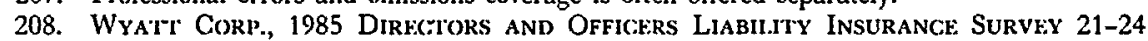

(1985).

209. Id. at 21 (exclusion reported by $40 \%$ of survey participants).

210. Wall St. J., Nov. 20, 1985, at 33, col. 4; see also infra text accompanying notes 213-15. 
ance because it is the cities that are without dump sites and the directors of firms not involved in tender offers that would drop out of the risk pool in order to self-insure if the insurance premium were increased to provide coverage for cities or directors exposed to these claims.

Similarly, the adoption of a claims-made policy narrows the risk pool by excluding coverage of the long tails of liability exposure that are increasingly common in chemical, pharmaceutical, and hazardous waste industries. A claims-made provision limits coverage to claims filed during the policy term alone. Thus, the provision cuts off insurance for losses resulting from the current activities of the insured that become manifest at some later period, after the insurance policy has expired. The basic claims-made policy provides coverage for current claims from past activities of the insured, although it is often attended by a separate "retro-date" provision, which cuts off coverage of losses occurring prior to some specified date in the past. The retro-date provision is crucial to a claims-made policy in order to avoid the adverse selection incentives of firms that, knowing or suspecting claims to be imminent, purchase substantial amounts of claims-made coverage. ${ }^{211}$

The adoption of claims-made policies and retro-date provisions are responses, in part, to the substantial disagreement and continuing uncertainty among United States jurisdictions with respect to whether a provider's liability dates from the occurrence of the injury or its manifestation. In contexts of cumulative disease, the determination of the "occurrence" of the injury is inherently difficult, and has itself generated substantial litigation among insurers. Moreover, some courts have refused to choose between occurrence and manifestation theories in favor of holding insurers, however related to the loss, liable for coverage. ${ }^{212}$ These various approaches all increase the variance of risk and severely threaten the survivability of risk pools. Several insurers, heavily involved in asbestos coverage, have been overwhelmed by the increase in risk and have been bankrupted.

The adoption of claims-made policies is a way to salvage some form of insurance availability in the face of extreme uncertainty over risks of this nature. ${ }^{213}$ The insurance industry seems to be evolving three basic forms of claims-made policies_called the "maxi," "midi," and "mini"-which illustrate the struggle of insurers to search out some particular set of low-

211. In this respect, the retro-date provision serves a similar function as a provision excluding pending or prior litigation.

212. Keene Corp. v. Insurance Co. of N. Am., 667 F.2d 1034 (D.C. Cir. 1981), cert. denied, 455 U.S. 1007 (1982).

213. The widespread adoption of claims-made policies, so hotly contested in the insurance industry, has not been appreciated for its role in extending insurance availability. See, for example, the discussion in the Wall St. J., Nov. 20, 1985, at 33, col. 4. 
risk insureds who can support a risk pool. ${ }^{214}$ The "maxi-tail" claimsmade policy guarantees supplemental five-year coverage for claims and occurrences after the end of the policy period. The "midi-tail" claimsmade policy provides coverage if the occurrences (but not claims) are reported to the insurer within sixty days after policy termination. The "mini-tail" claims-made policy offers the supplemental sixty-day coverage only for claims, after which coverage terminates. ${ }^{215}$ These various versions of the claims-made policy, like the more specific exclusions of insurance coverage, represent efforts to locate a set of insureds that will sustain a risk pool.

Each of these major changes in insurance availability, then, is a method to narrow insurance risk pools in the face of the increasing legal risk generated by modern tort law. Specifically, these contractual devices reduce variance in risk for the purpose of making insurance available to low-risk parties in the population of insureds. They are efforts to reduce adverse selection, and thus to prevent the unraveling of insurance markets that would occur if low-risk members of insurance pools were to exit.

The unraveling process would consist of the lowest-risk members of the pool dropping out, which, in turn, would necessitate premium increases. The premium increases would be followed by a new set of lowest-risk members dropping out; then, further increases in premiums; and so on, in successive episodes of withdrawals and premium rises. Of course, as lowrisk members withdraw, the constituency of the pool becomes further concentrated among high-risk members.

There is substantial evidence from the current crisis of the unraveling process at work. Reports from a variety of insurance markets show the progressive convergence of insurance premiums towards the level of aggregate insurance coverage offered by the policies. Professional malpractice premiums, for example, have increased from $\$ 44,000$ for $\$ 1$ million aggregate coverage (premium-to-coverage ratio of 0.044 ) to $\$ 50,000$ for $\$ 500,000$ coverage (premium-to-coverage ratio of 0.1 ). ${ }^{216}$ W.H. Brine Co., a manufacturer of sports equipment, was offered a premium of $\$ 200,000$ for $\$ 1$ million coverage (premium-to-coverage ratio of 0.2 ), up from $\$ 8,000$ for $\$ 25$ million (premium-to-coverage ratio of 0.00032 ) a year ear-

214. These policy terms are described in M. Aickin, Claims Made Wordings: How Appropriate Are They to Liability Problems? (1986) (unpublished paper presented at Seminar on Liability, Insurance and Safety Regulation, The Geneva $\Lambda$ ssociation, $\Lambda$ pr. 7, 1986). For the most recent formulation, see InSURANCE INFORMATION INSTrTUTE, InSURANCE: Nkws: ISO BROADENS CGL CoveraGe AND Consumer Pro'trcitons; Rrgul.ators Intrend to Approve: Program (Jan. 14, 1986) (describing ISO and NAIC draft claims-made policies).

215. Id.

216. Wall St. J., Jan. 21, 1986, at 1, col. 1. 
lier ${ }^{217}$ Mississauga, Ontario is charged a premium of $\$ 1.6$ million for its $\$ 7$ million aggregate coverage (premium-to-coverage ratio of 0.23 ). ${ }^{218}$ In some markets the premium-to-coverage ratio is even greater. The city of Hartford, Connecticut pays $\$ 1.8$ million for $\$ 4$ million aggregate coverage (premium-to-coverage ratio of 0.45). ${ }^{219}$ Business Insurance reports that one municipality is paying a premium of $\$ 695,000$ for $\$ 1$ million coverage (premium-to-coverage ratio of 0.695). ${ }^{220}$ Perhaps most incredibly, Specialty Systems, Inc., an asbestos removal firm, is charged a liability premium of $\$ 460,000$ for $\$ 500,000$ coverage (premium-to-coverage ratio of $0.92) .^{221}$

A convergence of the policy premium to the policy coverage limit provides strong proof that low-risk members are departing from the insurance pool and that the pool is about to unravel completely. Indeed, in the case of Specialty Systems, the premium-to-coverage ratio of 0.92 indicates that the insurance function has essentially ceased altogether; the premium payment is a form of savings in which the insurer is promising eight percent interest for what both parties must believe is a certain loss. ${ }^{222}$

Yet even these barely viable risk pools do not include the highest-risk members of the population. The examples above represent premium-tocoverage ratios for insurance policies written after deductibles have been increased, aggregate limits lowered (as in the professional malpractice and municipal coverage examples above), ${ }^{223}$ and specific coverage exclusions expanded. Thus, the largest number of high-risk members have already been excluded from these pools.

The policy premium converges with the level of aggregate coverage, of course, because low-risk members have dropped out of the risk pool, despite the efforts of the insurer to narrow the range of risks. The W.H. Brine Co., for example, refused to pay the $\$ 200,000$ premium for the offered $\$ 1$ million coverage, in favor of self-insurance. ${ }^{224}$ Brine obviously believed that the premium it was charged was greater than the expected risk it was adding to the pool.

Virtually all commentators have been puzzled by the extraordinary increases in insurance premiums that were instituted within a very few months in late 1985 and early 1986 . These unusual premium increases

\footnotetext{
217. New York Times, Mar. 8, 1986, at 35, col. 3.

218. Toronto Star Field, Feb. 20, 1986, at $\Lambda 7$.

219. Sorry, Your Policy Is Cancelled, supra note 2, at 17.

220. Bus. Ins., July 1, 1985, at 12.

221. Sorry, Your Policy Is Cancelled, supra note 2, at 18. For an explanation of why this company would pay for such a policy, see infra note 222 .

222. Apparently, the company chose this form of savings because "customers demand proof of insurance before they will give Specialty any business." Id.

223. See supra text accompanying notes 201-10.

224. N.Y. Times, Mar. 8,1986 , at 35 , col. 3 .
} 
constitute the best evidence in favor of the (otherwise implausible) collusion and financial manipulation theories of the crisis. In addition, these premium increases are the most damaging evidence to the Justice Department's effort to link the crisis to tort law, since there is no conceivable correspondence between changes in past tort judgments (and little correspondence to plausible future judgments) and premium increases of multiples of four, ten, twenty and more.

Comparing percentage changes in premiums to percentage increases in past or in future expected claims, however, rests on an unsupportable empirical presumption. Percentage changes in premiums will correspond to percentage changes in past or future claims only if the set of insureds remains constant over the compared periods. If, instead, there is a reconstitution of the insurance risk pool, the premium will change even if past or future claims remain constant.

The extraordinary increases in premiums within an exceptionally short period are the best evidence of the effect of expanding tort law on the constitution of commercial casualty insurance pools. The most plausible explanation for these unusual increases is the rapid departure of low-risk insureds from commercial casualty pools. As the low-risk members drop out, the unraveling process begins. Premiums skyrocket.

At a point after some number of low-risk members have fled the risk pool, the pool cannot survive. The risks become uninsurable. The multiple recent instances of the withdrawal of insurance coverage altogether are examples of the effect. The refusal of some insurers to offer coverage at all for day care, municipal, and directors' and officers' liability, among others, is conclusive evidence of the breakdown of the insurance function. ${ }^{225}$

When market insurers refuse coverage, a provider is left with little choice: it can discontinue provision of the product or service-as some providers have, described above ${ }^{226}$-or it can continue self-insured. For a relatively high-risk provider, self-insurance is very costly: the costs include the (not heavily) discounted risk of bankruptcy. Yet it may still be sensible for providers to run these risks, especially where they have made substantial non-salvageable investments in human or other forms of capital.

Since 1986, in many commercial lines denied market coverage, providers have joined together to form industry-wide mutual insurance groups. The mutual groups of the relatively high-risk, which have been denied

225. The reduction of aggregate policy limits and the expansion of specific exclusions, of course, are forms of partial withdrawal of coverage. They represent increasingly desperate efforts of insurers to ward off the unraveling of insurance pools as risks generated by increasing legal exposure continue to rise. Where insurers are unable to discover ways to isolate low-risk members, they must withdraw the offer of coverage altogether.

226. See supra text accompanying notes 176-84. 
market insurance coverage, are to be distinguished from mutuals formed by relatively low-risk insureds, described above, ${ }^{227}$ who have dropped out of the commercial risk pools generating the initial unraveling. Low-risk mutual groups are formed because their members find being pooled with the high-risk more costly than it is worth. High-risk mutuals, in contrast, are formed as basically the last option prior to termination of the activity. High-risk mutuals have been formed in the drug, chemical, railroad, utility, hazardous waste, banking and thrift industries. ${ }^{228}$ Mutual groups of this nature have been formed by municipalities and other governmental entities. ${ }^{229}$ And they have been formed in several unique specialty occupations denied market insurance, such as nurse midwives, ${ }^{230}$ and other highrisk specialties. ${ }^{231}$

Mutuals are insurance companies owned by the insureds themselves. The most prominent of scholarly descriptions of the mutual form derives from studies of the large life insurance mutuals, in which the insureds receive dividends according to the loss experience of the firm for the year, and thus share downside insurer risks to the extent of the premiums they pay. ${ }^{232}$ The industry-wide mutuals formed recently in response to the denial of market insurance coverage share much greater downside risks. These mutuals, typically, incorporate assessment provisions according to which the insureds are obliged, in addition to premiums, to contribute towards the payment of subsequent claims for which the existing assets of the mutual are insufficient. Industry-wide mutuals thus are a way of distributing the risks of a single firm across the set of the firm's competitors. The mutual form provides that an adverse loss experience by a single firm is inflicted on the industry as a whole, but does not upset competitive balance within the industry. ${ }^{233}$

In my view, the recent increase in adoption of the mutual form derives from the different way mutuals diversify risks, and illustrates again how modern tort law has impaired the insurance function. Recall that the ag-

227. See supra text accompanying notes 190-93.

228. Wall St. J., Jan. 21, 1986, at 31, col. 1. Industry groups denied commercial liability insurance have pressed for Congressional enactment of a Risk Rentention $\Lambda$ ct facilitating the group mutual form. See Gesil, House Ready To Act on Risk Retention Bill, Bus. INS., July 28, 1986, at 1. Dennis Connolly of Johnson \& Higgins, an insurance broker actively involved in the formation of risk retention groups, describes those that have successfully formed such groups "the cream of the dregs." Public comment at conference "Solutions to the Insurance Crisis: Exploring the Link Between Tort Reforms and Insurance Regulation," Program in Civil Liability, Yale Law School, February 28, 1987.

229. See infra text accompanying notes 237-39.

230. N.Y. Times, Mar. 31, 1986, at 37, col. 2.

231. Posner, Trends in Medical Malpractice Insurance, 1970-1985, 49 Law \& Conremp. Prons. 37, 42-44 (1986).

232. See generally Hansmann, The Organization of Insurance Companies: Mutual Versus Stock, 1 J.L. Econ. \& Orc: 125 (1985).

233. Id. al 148 . 
gregation of uncorrelated risks exploits the law of large numbers to concentrate the probability density function of loss around its mean, reducing effective risk and permitting more accurate prediction of expected loss. Industry-wide mutuals also aggregate risks, but in an ex post fashion. Mutuals wait for losses actually to occur and then set an effective premium to cover them. If the risks brought by members of the mutual are uncorrelated, a similar aggregation function is achieved. The effective premiums paid by members of the mutual (after dividends or assessments) will equal the loss of each insured. As a general matter, therefore, the chief difference between common stock and mutual insurance companies is that common stock companies charge premiums according to expected loss and mutuals according to actual loss. ${ }^{234}$ As long as the risks brought by insureds are uncorrelated, the premiums will be identical.

Why have so many industries adopted the mutual form in recent years? As tort liability has expanded, risks have become increasingly correlated both within and across industries. If the risks of firms within an industry become highly correlated, a market insurer has no comparative advantage in aggregating them. The level of aggregated risks will equal or may even exceed the sum of the individual risks. The insurer may still achieve some gains by aggregating risks of one industry with risks of another industry. But if risks become highly correlated across industries-as they will where the legal liability of all corporate providers is expanded-the market insurer has no comparative aggregation advantage at all. Members of the industry are just as well off self-insuring. Indeed, adoption of the mutual form allows firms to continue operation until judgments are rendered bankrupting the industry, instead of paying debilitating premiums $e x$ ante set equal to expected loss.

Here again, the contrast between the insurance effects of first- and third-party sources is stark. Providing insurance through the third-party tort law mechanism, because it correlates risks, has the effect of threatening industries with bankruptcy. Bankruptcy results in the denial of insurance coverage to victims with claims. ${ }^{236}$ If the insurance were provided through a first-party mechanism, however, the risks of the victims could easily be made uncorrelated. ${ }^{236}$ The insurance function, as a consequence, could be maintained. The expansion of legal liability, thus, impairs the insurance function.

In commercial insurance lines, the shift toward the mutual form has

234. Hansmann alludes to this difference. Id.

235. Victim claimants against a bankrupt firm, of course, do receive some share of full tort law damages. Strictly speaking, the issue is whether this share is greater or less than the amount of firstparty coverage the claimants would have purchased.

236. For example, by first-party insurers deciding to insure only some number of workers exposed to risks of some particular cumulative disease. 
been concentrated in industries facing long tails of liability. Large numbers of government entities, however, have also joined together to form assessible mutuals. Municipalities in metropolitan Toronto have established a mutual self-insurance pool. ${ }^{237}$ Sheriffs in five counties of Missouri recently were forced to close their jails for several weeks until a mutual self-insurance pool was established. ${ }^{238} \mathrm{~A}$ group of municipal mutual pools in California has enrolled 350 of the state's 444 cities. $^{238}$

An individual government entity, such as a city, operates in the mutual form in a way slightly different from a private corporation. Some commentators seem shocked that many municipal entities are "going bare:" providing public services without any form of market or overt mutual insurance. ${ }^{240}$ But a governmental entity can use its taxing authority as a way to act as a mutual insurer over time. Many governmental entities can diversify risks seemingly more cheaply than can private corporations because they possess populations of taxpayers, more immobile than consumers, who can be levied to satisfy large liability judgments, either directly or through revenue bonds. The citizenry may well approve of this form of mutual insurance. Voters in Blue Island, Illinois, for example, recently turned down a proposed 30 percent increase in property taxes, levied to collect funds to pay market insurance premiums. ${ }^{241}$ The defeat of the proposal represents the (presumably informed) decision of voters to selfinsure in the mutual form. Of course, hinging a government entity's tax needs to the accident rate introduces greater risk to property ownership and thus increases its costs. The advantages of the mutual form described above, however, may make government self-insurance cheaper than market insurance. Obviously, entities with larger tax bases will find this form of self-insurance relatively more attractive. ${ }^{242}$ Cities with relatively smaller tax bases are more likely to join the mutual pools described above.

Many governmental entities have one further advantage over private corporations in coping with the increase in the variance of risk generated by modern tort law. Governmental entities seem more able to persuade legislatures to grant them exemptions from the effects of tort law, perhaps because the specific beneficiaries of limiting municipal liability-city voters-are more highly concentrated politically than consumers of any single product. Several state legislatures, for example, have recently enacted

237. See Oniario Task Force: on Insurancy, Final. Reporit, May 1986, at 370-71.

238. Sorry, Your Policy Is Cancelled, supra note 2, at 18.

239. Bus. Ins., Jan. 26, 1987, at 16; see also Bus. INs., July 15, 1985, at 3, for a description of the 191-city Texas Municipal League.

240. See Bus. Ins., supra note 195, at 1.

241. Sorry, Your Policy Is Cancelled, supra note 2, at 18.

242. Bus. INs., July 8, 1985, at 1, 30. 
statutes changing liability standards and damage measures for actions brought against public entities. ${ }^{243}$

There is no clear conceptual justification to judge against different standards torts committed by government versus private employees. Indeed, as suggested by the apparent greater frequence of adoption of the mutual form, governments seem more able to tolerate heavy liabilities through self-insurance than do companies. The point, rather, is that both corporate and governmental insurance liability are inferior to first-party insurance liability. Municipalities, because of their superior political influence, especially in times of independent political pressure to tighten budgets, are more able than corporate providers to obtain legislation shifting the insurance burdens of modern tort law back to first-party sources.

\section{The Insurance Grisis: Its Gause and Gure}

\section{A. Cause and Effects}

By my count, the industries that have been most seriously affected by the current insurance crisis are those dealing with hazardous materials, including toxic wastes, asbestos, and chemicals; manufacturers of pharmaceuticals and related products; hospitals, physicians in certain specialties such as obstetrics and anesthetics, and related practitioners such as nurse midwives; municipalities and other governmental entities; assorted general and machine manufacturers; general aircraft manufacturers; ski lift operators; day care centers; corporate directors and officers; liquor establishments; and publishers. There are vast lines of insurance that have been totally untouched by the crisis. All first-party insurance lines-auto, health, life, disability-have been largely unaffected. Even some thirdparty liability lines, such as auto and workers' compensation have been unaffected. Gan these different industry experiences be explained by the progressive shift from first-party toward third-party tort law insurance?

Obviously, the absence of crisis in first-party insurance lines is consistent with the theory. The other phenomena are also consistent. The industries most seriously affected by the crisis are those for which the risks have become essentially uninsurable. The risks of tort liability are uninsurable for two separate reasons. One set of firms affected by the crisis have been made subject to tort liability for claims that do not result from probabilistic causes. I have mentioned earlier that insurance is only feasible where a loss has a probabilistic character. Put simply, insurers have no comparative advantage in providing coverage for non-probabilistic losses; there are no efficiencies gained from aggregating that nature of claims. The inabil-

243. See infra note 261. 
ity to insure tort claims against day care centers for injuries suffered from sex abuse has already been explained in these terms. Other industries in the list, however, suffer similar problems. The liability of liquor establishments for injuries from drunken behavior, in particular drunk driving, raises severe insurability problems. The frequency of harm-causing intoxication is most directly influenced by those to whom the insured taverns serve liquor. Although there may be some random component with respect to the extent of damage caused, the randomness may easily be swamped by the effect of the specific decisions of tavern clients. ${ }^{244}$ Directors' and officers' insurance and publishers' defamation insurance is of the same nature. While there is some random component to such claims and to the vulnerability of the insured to such claims, there is also heavy influence of the intentional actions of the insured itself.

The second principal reason that tort liability is uninsurable for the industries listed above is that the variance of risks has been so expanded by tort liability that the risk pools are unsupportable. Many of the industries most severely affected by the insurance crisis are those subject to tails of liability extending over long periods of time, thus incorporating an extraordinarily wide range of potential outcomes. The liability of asbestos manufacturers for injuries from asbestos ingestion exemplifies the problem. Obviously, no real insurance against asbestos tort liability is being written today. ${ }^{245}$ Chemical manufacturers, pharmaceuticals, and the various medical specialties all face similar tails of liability. These industries, of course, have been the first into which the claims-made policy has been introduced, cutting off the liability tail. In contrast, there is no need for such policies in third-party auto, domestic casualty, or even workers' compensation insurance because there is no tail of liability following an auto collision, a slip and fall, or even most workplace injuries. ${ }^{246}$

Municipalities and governmental entities face closely related problems. Except for claims related to the supervision of hazardous waste disposal, there is no long tail of municipal liability extending over time. As liability for governmental supervisory behavior has been expanded, however,

244. Put differently, insurance markets cannot be sustained where there is a substantial range for moral hazard. This is the reason that virtually all policies, including first-party policies, exclude coverage of intentional or reckless acts. See also infra note 249 for a discussion of the insurance difficulties of dramshop liability.

245. It is possible that insurance might be sold to provide a form of claims adjustment or to capitalize on the variance in time that claims are filed, much like the sale of insurance to MGM after the fire at its MGM Grand Hotel in the early 1980's. For a contrasting interpretation of the ex post insurance of the MGM Grand, see Mayers \& Smith, supra note 127, at 285-86.

246. Workers' compensation may involve long tails of liability (the asbestos workers were workers), but generally limits damages to amounts far less than those available under tort law theories of recovery, incorporates deductibles and coinsurance features, and does not typically employ the tort system for the delivery of benefits. Though nominally paid for by the employer, workers' compensation much more closely resembles first-party than third-party tort law insurance. 
something resembling a liability tail has been created. Governmental entities supervise, in one form or another, virtually all activities of the society. Insuring governmental entities requires the prediction of the range of potential plaintiffs who might successfully bring suit. The problem of prediction is made more acute where the combination of the doctrines of joint and several liability and pure comparative negligence expose the governmental entity to full liability though the entity's role in, say, the design of a road, the purchase of playground equipment, or the operation of its police force contributed in only a minor way to the injury.

To an insurer, the existence of a broad and indefinite range of potential plaintiffs is no different from a long tail of injuries extending over time. The expansion of governmental liability makes the range of potential outcomes extremely broad, requiring exaction of a very high premium. At some point, there is no advantage to a single municipality in paying this risk premium ex ante, in contrast to ex post self-insurance or operation with others in the mutual form. ${ }^{247}$ Of course, those municipalities facing lower risks-which may be those whose size allows them to serve the insurance function internally ${ }^{248}$ - will be the first to drop out of the market insurance pool, forcing premiums up and initiating the unraveling process.

The miscellaneous set of other industries-machine manufacturers, ski lift operators, general aircraft-are not subject to long tails of tort liability, but they are similarly subject to vastly expanded risk pools as a result of increased tort liability. Here another insurance effect is likely to be at work. Within these industries the smaller, rather than the larger, firms have been most seriously affected. It is more difficult for insurers to underwrite the risks of smaller than of larger firms, because the insured itself, given its small set of consumers, provides little of the pooling function. ${ }^{248}$ As a consequence, the insurer must identify other firms or industries whose liability risks are uncorrelated in order to gain the pooling efficiencies of insurance. The expansion of modern tort law, as described earlier, greatly hampers this insurance effort because it affects all corporate operations and, thus, correlates (reduces the independence of) risks even within different industries.

The example of the smaller firms and industries, however, suggests that the insurance crisis is a far broader phenomenon than might even be suspected from the reporting of the loudest complaints. Again, I measure the

247. See supra text accompanying notes 232-42.

248. See generally Cuomo Comm'N, supra note 17, at 35-39 (discussing self-insurance by New York City).

249. The relatively greater difficulty of insuring small entities may also explain the refusal of some insurers to offer dramshop coverage. 
"crisis" by those loss-generating activities which cannot be insured by means of third-party tort law insurance, but which could support firstparty victim insurance. It is my view that commercial casualty markets in their entirety have been made fragile by the expansion of modern tort law. The firms most seriously affected in late 1985 and early 1986, as interest rates dipped slightly, were those whose activities generated long tails of liability or whose small size required a greater insurer role. If these explanations are accurate, however, the scope of the crisis can easily extend more broadly throughout commercial casualty fields. As interest rates dip further, or as corporate tort liability is further expanded, the crisis is likely to extend to firms of larger size or firms with shorter tails of liability.

Who has suffered most from these developments? It is clear in my mind that the greatest harm from the expansion of tort liability and the consequent shift from first- to third-party tort insurance coverage has been suffered by the poor and low-income within the consuming population. The increase in market insurance and self-insurance costs leads to increases in the price level of virtually all commodities. In some cases, these increases will effectively price low-income consumers out of the market for the product altogether. Increases in product prices shrink the purchasing dollar and, in proportionate terms, shrink it more severely for the poor.

The increase in insurance costs reduces the availability of products or services for the poor in still more ways. The unwillingness of obstetricians to perform normal deliveries for less than $\$ 1200$, noted earlier, more severely affects those individuals for whose deliveries Medicare will pay $\$ 507$ than those consumers able to pay the full cost by private negotiation with the doctor. Similarly, the termination of midwife services because of the absence of insurance is relatively less troublesome to those who can afford to substitute licensed physicians or full-priced obstetricians.

More generally, even if the low-income are able to continue to pay the insurance-enhanced prices of products, they are harmed. The poor and low-income are much more likely to be paying a premium that exceeds the risk they bring to the pool under third-party than under first-party insurance coverage, because of the difficulty providers face in segregating risk pools. No one today would seriously propose that all citizens pay an identical life insurance premium where some of the beneficiaries-the high-income-would receive greater total benefits. No one would urge that all individuals pay the same disability premium regardless of expected income. No one would seriously propose that all homeowners pay the same fire premium regardless of home value, or that all drivers pay the same auto premium regardless of car value. Yet this is exactly the regime of life and disability insurance provided by modern tort law. Mod- 
ern tort law forces all consumers to pay the same third-party insurance premium for product- and service-related coverage for losses leading to injury, disability and death.

Wealthy and high-income members of the consuming population are also harmed by the shift to third-party coverage. Admittedly, in individual instances, relatively high-income members may gain from paying a premium averaged for a pool containing some relatively low-income members. More generally, however, the broadening of risk pools characteristic of the shift to third-party coverage harms the high-risk of the insured population as well, because it reduces the availability of insurance in all contexts. The high-income do not benefit when jails and parks are closed or, for that matter, when relatively low-cost products and services, such as vaccines, are withdrawn from the product market.

Nevertheless, it is the poor who are most severely harmed. It is not surprising that the crisis has heavily disrupted the provision of municipal and other governmental services. Because such services are generally provided without charge, it is impossible directly to pass on to users the costs of increased insurance premiums. Yet it is also because municipal services are provided without charge that they are of particular importance to the lives of the poor.

The motivation for the judicial expansion of third-party liability during the early 1960's was to protect the poor within the consuming population by providing them with a form of insurance that they might not otherwise obtain. ${ }^{250}$ At the time of the first adoption of the strict liability standard, however, our society had not introduced the array of social insurance programs available today, and the courts may not have perceived the wide range of privately available first-party health and disability coverage. Today, the number failing to possess basic health coverage is very small. ${ }^{261}$ Our society covers the poorest of the poor through Medicaid, Medicare for the aged, and General Assistance. Although it is estimated that 18 -million individuals totally lack health care insurance, ${ }^{252}$ it is unknown how many fail to qualify for Medicaid while healthy and able to maintain employment, but would qualify if, through injury or illness, their employment were to cease. This group is uninsured only formally: They are uninsured until they need health insurance, at which time they become insured. ${ }^{283}$ A more precise 1982 telephone survey of families found only 1.5

250. See Enterprise Liability, supra note 28, at 505-19.

251. The figure 35 million is often mentioned, but represents those who fail to possess insurance for any period throughout the year. It overstates the number denied medical care because of the absence of insurance. See SEN. SUBCOMM. ON THE AGED, supra note 136.

252. Id.

253. Of course, because our society prevents collection of some sets of claims (e.g., elimination of imprisonment for debt, bankruptcy protection), there will always be members of the population who 
percent in which any family member had been denied health care for financial reasons. ${ }^{254}$ Disability coverage in the U.S. appears more spotty, at least for non-job related injuries. But there are no studies indicating the number of individuals failing to possess private disability coverage who would not be covered by government disability programs. It is a crucially important empirical question exactly how many in our society remain unprotected for basic health and disability losses, although the number appears to be quite small and the definition of the set quite peculiar. ${ }^{255}$ It is at the least unusual to believe that an effective and comprehensive way to provide care to such individuals is through tort system recoveries for injuries from products or services. ${ }^{256}$

\section{B. Cure}

Within the past eighteen months, forty-two state legislatures have enacted some form of tort reform legislation. A detailed discussion of this legislation is beyond the scope of this paper, although I will briefly review the effects of these reforms on insurance markets. The most significant changes in the law are (1) monetary caps on non-economic damages, ${ }^{267}$ (2) caps or other limitations on punitive damages, ${ }^{258}$ (3) abrogation of

are better off uninsured. See also Keeton \& Kwerel, supra note 155.

254. See Sin. SUbComm. ON THE AGED, supra note 136.

255. Id.

256. These issues are addressed in more detail in Priest, Protecting the Poor through Tort Law, (1987 unpublished manuscript on file with author).

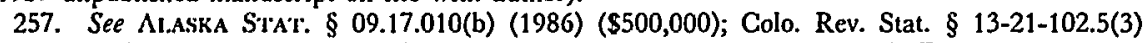
(Supp. 1986) $(\$ 500,000$ if clear and convincing evidence, otherwise $\$ 250,000)$; Fla. Stat. $\$ 768.80$ $(\$ 450,000)$. But see Smith v. Department Ins., Fla. Sup. Ct. No. 69,551 (April 23, 1987) (holding cap unconstitutional as violating right to access to courts and right to trial by jury); Hawaii: CCH Prod. Liab. Rep. $\Uparrow 91,230$ (to be codified at Haw. Rkv. Srat. $\S 663$ (award for pain and suffering in selected tort actions limited to $\$ 375,000)$; Kans. Stat. Ann. $\$ 60-3407$ (1986) (\$250,000, medical malpractice, subject to cost of living adjustment); Maine, LD2080, $1986(\$ 250,000$, alcohol servers (includes some economic losses)); Md. Ann. Code art. x, § 11-108(B) (\$350,000); Massachusetts, H.6172 (\$500,000 except where substantial impairment or disfigurement); Michigan, H.5154 (\$225,000, medical malpractice (with exceptions)); Minn. Stat. Ann. $\$ 549.232$ (West Supp. 1986) ( $\$ 400,000$ on intangible lossess); Rev. Stat. Mo. \$ 538.210 (1986) ( $\$ 350,000$ medical malpractice); N.H. Rev. Stat. Ann. \$ 508:4-d (Supp. 1986) (\$875,000); South Dakota, S.282, 1986 (\$1,000,000 medical malpractice (all damages)); Utah, S.111, 1986 ( $\$ 250,000$ medical malpractice) (also total damage limits on dram shop liability); Wash. Rev. Code Ann. $\S 4.56 .250(2)$ (West Supp. 1987) (multiple of average annual wage times life expectancy); West Virginia, S.714, $1986(\$ 1,000,000$ medical malpractice) $(\$ 500,000$, political subdivisions); Wisconsin, Special Session AB8, 1986 $(\$ 1,000,000)$. The Supreme Court of Canada has adopted a cap on non-economic losses by judicial decision (indexed, currently equal to roughly $\$ 215,000$ Canadian). Andrews v. Grand \& Toy Alberta, Lid., (1978) 83 D.L.R. (3d) 452; Thornton v. School Dist. No. 47 (1978) 83 D.L.R. (3d) 609.

258. AI.ASKA STAT. $\$ 09.17 .020$ (1986) (no punitive damages unless supported by clear and convincing evidence); Col.o. Rrv. SrAT. \$\$ 13.21-102(1)(a) and -102(4) (Supp. 1986) (not greater than compensatory, one-third to state general fund); Fl.A. STAr. $\$ 768.73$ (1986) (not greater than three times compensatory, 60\% to state fund); Hawaii, S.1, 1986; It.t. Rev. STAT. ch. 110, para. 2-1207 (allowing trial court to enter remittitur and conditional new trial); Iowa CoDE $\S$ 668A.1 (requiring jury to answer special interogatories before awarding punitive damages); MINN. STAT. ANN. $\S$ 549.191 (West Supp. 1986) (punitive damages may not be sought in original complaint; complaint 
joint and several liability, ${ }^{259}$ (4) elimination of the collateral source rule, ${ }^{280}$ and (5) amendments to substantive liability standards for specific activities such as municipal operations, dramshops, or non-profit organizations. ${ }^{261}$ If the source of the crisis is the shift from first- to third-party tort law insurance sources, how effective will these reforms be?

The various tort reform statutes have been supported by a coalition of business and insurance interests, chiefly on the simple ground that modern tort liability is excessive and unfair. ${ }^{262}$ Observers have not generally appreciated, however, that each of these reform provisions will affect insurance markets in a similar way: they reduce the variance in insurance risk pools. Obviously, caps on non-economic and punitive damages reduce the range of potential liability outcomes. Similarly, abrogation of the doctrine of joint and several liability in favor of strict comparative fault reduces the risk that any one of a group of joint defendants will ultimately be required to satisfy the entire judgment. Deducting first-party insurance benefits from tort judgments will also reduce risk pool variance. More generally, of course, altering liability standards to make recovery more difficult for plaintiffs will diminish expected liability. To the extent that variance in risk pools is reduced, third-party tort law insurance becomes more supportable.

These reforms, while helpful, constitute only partial contributions toward solution of the problems caused by modern tort law. The provision of insurance through tort law has undermined insurance markets. In my view, these markets will not be fully restored until these insurance issues are dealt with more systematically. The insurance function must be ex-

may be amended to include punitive damages only if court finds prima facie evidence at hearing on motion to amend); Missouri S.742 (outlawed in product liability actions); N.H. Rrv. Srat. ANN. \$ 507:16 (Supp. 1986) (no punitive damages to be awarded in any action unless otherwise provided by statute); OKt.A. STAT. ANN. tit. 23, $\$ 9$ (West 1987) (equal to compensatory damages unless court finds clear and convincing evidence of reckless disregard for rights of another); S.D.: Prod. Liab. Rep. (CCH) If 94,385 (1986) (1986 S.D. Laws S.B. 280; only if court finds reasonable basis to believe wilful, wanton or malicious conduct occurred can discovery be had relating to punitive damages).

259. Cot.o. Rrv. STAY. § 13-21-111.5 (Supp. 1986); F1.A. STA\%. § 768.81; Hawaii: CCH Prod. Liab. Rep. II 91,210 (1986) (to be codified at Haw. Rrv. Srar. \$ 663) (for noneconomic damages except in specified types of cases); id. 1 91,433 (1986 Ill. Laws S.B. 1200 (except for medical expenses and when tortfeasors' fault is greater than or equal to $25 \%$ of total fault); Mo. Rrv. S'TAT. \$ 538.230 (1986); Utah Laws 78-27-38 (Supp. 1986); Wyo. C.C.P. \$ 1-1-109 (1986); see National. ConfkRENCF: OF STATr: LkGisi.A'TURES, supra note 25.

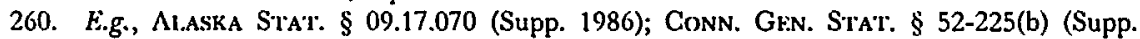
1987); Minn. STat. $\$ 548.36$ (Supp. 1987); see Natrional. Confrerknce of STate Leislatures, supra note 25.

261. E.g., Municipal Liability: GA. Srar. § 36-33-1 (Supp. 1986); LA. STAT. § 9:2798.1 (1985); Dramshops: N.H. SrAT. 507-F:1 et. seq. (Supp. 1986); Il.. SrAl. 43 II $135 \$ 6.21$ (1986); Non-

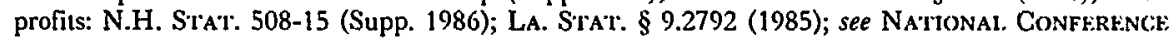
OF STATr: Ligisi.AlUREs, supra note 25.

262. The Need for Legislative Reform, supra note 64, at 15-43 (discussing erosion of fault-based liability and increasing damage awards). 
cised from tort law altogether. None of the recent statutory reforms achieves that effect.

A cap on non-economic damages, for example, does shift tort damage awards to more closely resemble levels of insurance purchased in firstparty markets. In first-party markets, however, no one purchases any coverage of non-economic losses. Thus, even if non-economic damages in tort law are capped at $\$ 450,000$ or $\$ 250,000$, tort law continues to provide a very substantial level of excess insurance coverage.

Similarly, limitations on punitive damages may reduce risk pool variance to some extent. In my view, however, it is appropriate not only to restrain, but to prohibit, punitive damage awards in product liability and other tort contexts. Punitive damage awards can be justified only where there is some likelihood (1) that normal damage measures cannot measure loss accurately-such as in defamation cases; ${ }^{263}$ (2) where there is substantial difficulty in detecting the existence of the injury-such as in fraud or, perhaps, some antitrust actions; or (3) where other incentives are needed to stimulate litigation. ${ }^{284}$ For cases in which manufacturers or other providers have deliberately misrepresented product safety or effectiveness-such as the MER-29 cases-punitive damages should be awarded on grounds of the fraudulent behavior itself, not on grounds of the defective character of the product. There is no further need to award punitive damages in typical products and service liability contexts. In this respect, a legislative maximum on punitive damage awards or limitations on the conditions under which punitive awards may be made, constitutes only a partial solution.

The source of the insurability crisis is not the level of damages alone. Rather, the diffuse and indiscriminate expansion of substantive tort liability has led to the unraveling of insurance markets in an increasing number of contexts. This unraveling can be arrested only if substantive standards of liability are redefined to focus exclusively on the accident reduction goal. In my view, modern tort law provides inadequate controls on the accident rate and simultaneously creates a tort law insurance regime that disrupts insurance markets and harms the poor. The objectives of tort law reform are uncontroversial: to reduce the accident rate and to provide a more coherent and comprehensive regime of compensation insurance. These objectives cannot be achieved by tinkering with damage measures and by limited changes in liability standards for particularly

263. Note that my example of defamation extends only to measures of damages. In the defamation area, as in other areas of tort law, there has been a substantial expansion of substantive liability on insurance grounds that is very difficult to defend.

204. See generally Ellis, Fairness and Efficiency in the Law of Punitive Damages, 56 S. CAL. L. REv. 1, 10 (1982). 
sympathetic sets of defendants, such as govermental entities, dramshops or non-profit organizations. Instead, modern tort law must be reformed systematically: by a complete redefinition of liability standards to better achieve accident reduction and insurance. ${ }^{285}$

265. For a further explanation of my views on this subject, see G. Priest, Modern Tort Law and Its Reform (unpublished manuscript on file with author, 1987). 